Gabriel Marcelino da Silva Neto

\begin{abstract}
AVALIAÇÃO DOS PARÂMETROS FUNCIONAIS E HISTOLÓGICOS ASSOCIADOS À EXPOSIÇÃO DO PEIXE BEIJUPIRÁ Rachycentron canadum (Linnaeus, 1766) A CONCENTRAÇÕES SUBLETAIS DE HIDROCARBONETOS POLICÍCLICOS AROMÁTICOS (HPAs)
\end{abstract}

Dissertação apresentada ao Programa de Pós Graduação em Biologia Celular e do Tecidual do Instituto de Ciências Biomédicas da Universidade de São Paulo, para obtenção do Título de Mestre em Ciências.

São Paulo

2015 
Gabriel Marcelino da Silva Neto

\section{AVALIAÇÃO DOS PARÂMETROS FUNCIONAIS E HISTOLÓGICOS ASSOCIADOS À EXPOSIÇÃO DO PEIXE BEIJUPIRÁ Rachycentron canadum (Linnaeus, 1766) A CONCENTRAÇÕES SUBLETAIS DE HIDROCARBONETOS POLICÍCLICOS AROMÁTICOS (HPAs)}

Dissertação apresentada ao Programa de Pós Graduação em Biologia Celular e do Tecidual do Instituto de Ciências Biomédicas da Universidade de São Paulo, para obtenção do Título de Mestre em Ciências.

Área de concentração: Biologia Celular e Tecidual

Orientadora: Profa. Dra Maria Inês Borella

Versão Original.

São Paulo

2015 
DADOS DE CATALOGAÇÃO NA PUBLICAÇÃO (CIP)

Serviço de Biblioteca e Informação Biomédica do Instituto de Ciências Biomédicas da Universidade de São Paulo

(C) reprodução total

Silva Neto, Gabriel Marcelino da.

Avaliação dos parâmetros funcionais e histológicos associados a exposição do peixe beijupira Rachycentron canadum (Linnaeus, 1766) a concentrações subletais de hidrocarbonetos policlícos aromáticos (HPAs) / Gabriel Marcelino da Silva Neto. -- São Paulo, 2015.

Orientador: Profa. Dra. Maria Inês Borella.

Dissertação (Mestrado) - Universidade de São Paulo. Instituto de Ciências Biomédicas. Departamento de Biologia Celular e do Desenvolvimento. Área de concentração: Biologia Celular e Tecidual. Linha de pesquisa: Estresse-biomarcadores - HPAs- Alterações histologicas.

Versão do título para o inglês: Evaluation of functional and histological parameters associated to beijupira Rachycentrom canadum (Linnaeus, 1766) exposure to sublethal concentrations of policyclic aromatic hidrocarbons (PAHs).

1. Peixe 2. Petróleo 3. Estresse 4. HPAs 5. Alterações histologicas 6. Rachycentron canadum I. Borela, Profa. Dra. Maria Inês II. Universidade de São Paulo. Instituto de Ciências Biomédicas. Programa de Pós-Graduação em Biologia Celular e Tecidual III. Título. 
Gabriel Marcelino da Silva Neto.

Título da Dissertação: $\quad$ Avaliação dos parâmetros funcionais e histológicos associados a exposição do peixe beijupira Rachycentron canadum (Linnaeus, 1766) a concentrações subletais de hidrocarbonetos policlícos aromáticos (HPAs).

Orientador(a): $\quad$ Profa. Dra. Maria Inês Borella.

A Comissão Julgadora dos trabalhos de Defesa da Dissertação de Mestrado, em sessão pública realizada a considerou
( ) Aprovado(a)
( ) Reprovado(a)

Examinador(a): Assinatura:

Nome:

Instituição:

Examinador(a): Assinatura:

Nome:

Instituição:

Presidente: Assinatura:

Nome:

Instituição: 


\section{Certificado}

Certificamos que o protocolo registrado sob $n^{\circ} 185$ nas fls. 139 do livro 02 para uso de animais em experimentação, sob a responsabilidade do Prof(a) Dr(a)) Maria Inês Borella, Coordenador (a) da Linha de pesquisa "Avaliação dos parâmetros funcionais e histológicos associados à exposição do peixe Beijupirá Rachycentron canadum (Linnaeus, 1766) a concentrações subletais de hidrocarbonetos poliaromáticos (HPAs)" do qual participam o(s) aluno(s), Gabriel Marcelino da Silva Neto e a pesquisadora Ligia Maria Salvo, está de acordo com os Princípios Éticos de Experimentação Animal adotado pela Sociedade Brasileira de Ciência de Animais de Laboratório (SBCAL) e foi aprovado pela COMISSÃO DE ÉTICA NO USO DE ANIMAIS (CEUA) em 21.01.2013, com validade de 4 anos.

São Paulo, 24 de janeiro de 2013.
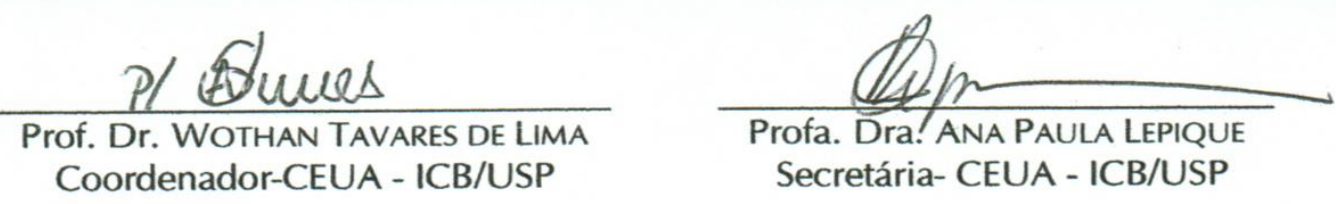
Aos meus pais Ester e Francisco, meus irmãos Paulo, Flavia e Eduardo e à minha noiva Jessica.

\section{DEDICO！}




\section{AGRADECIMENTOS}

À Profa. Dra. Maria Inês Borella pela orientação, amizade e oportunidade nessa etapa da minha vida.

Ao Prof. Dr. Jose Roberto Machado Cunha da Silva pela orientação, ensino, amizade e confiança.

À Pós Doutoranda Lígia Maria Salvo, por estar comigo nos primeiros passos, por me ensinar a colaborar nos meus projetos e pela amizade.

A todos os meus amigos do laboratório de Histofisiologia Evolutiva, por todos esses anos de convivência, apoio, amizade e respeito, tudo que uma família representa.

A todos os meus amigos do laboratório de Endocrinologia de Peixes, pela amizade e apoio.

À minha amiga Karina Fernandes Oliveira Rezende pela amizade e por todo seu apoio e incentivo nos momentos difíceis desse mestrado.

Ao meu irmão Felipe da Costa Souza pela amizade, apoio, incentivo e presença em todos os momentos difíceis inclusive nessa etapa.

À Joana Mona e Pinto pela amizade, apoio e sábios conselhos que me serão úteis por toda a vida.

À Emília Ribeiro, técnica de laboratório, pela amizade, apoio e ensino na preparação de todas as soluções utilizadas nesse projeto.

À Roberta Ferrari Mourão, técnica de laboratório, por me ajudar nos ensaios sobre os parâmetros estressores.

Ao Diogo Nader Palermo, técnico de laboratório, por me ajudar nos ensaios sobre os parâmetros estressores.

À Eloiza Rezende, pela amizade, confiança e incentivo.

À Renata Nascimento Gomes pela amizade, confiança e incentivo. 
Ao Departamento de Biologia Celular e do Desenvolvimento do Instituto de Ciências Biomédicas da Universidade de São Paulo pela oportunidade de desenvolver o projeto e a todos os professores pela ajuda indispensável.

À Petrobrás, por ceder o petróleo utilizado nesse projeto.

Ao Prof. Dr. Divinomar Severino, pelo auxílio com as amostras de petróleo.

À Profa. Dra. Allison Colquhoun, Prof. Dr. Fabio Siviero e Profa. Dra. Fernanda Ortis, por toda ajuda e sábios conselhos no exame de qualificação.

Ao Instituto de Química e ao Instituto de Biociências da USP por disponibilizarem os equipamentos para desenvolver esse projeto.

À Faculdade de Medicina Veterinária e Zootecnia da USP por disponibilizar os equipamentos para desenvolver esse projeto.

Ao Centro de Biologia Marinha da USP (CEBIMar/USP) por disponibilizar espaço e equipamentos para desenvolver esse projeto.

À Regina Valbom, pela amizade, paciência e apoio durante as etapas vitais desse projeto.

À Profa. Dra. Marilia Cerqueira Leite Seelaender e toda sua equipe pelo auxílio, amizade e por disponibilizar seu laboratório para desenvolver parte desse projeto.

À Profa. Dra. Renata Guimarães Moreira Whitton pelo auxílio, incentivo e disponibilizar seu laboratório para desenvolver parte desse projeto.

Ao Prof. Dr. Francisco Javier Hernandez-Blazquez por disponibilizar seu laboratório para desenvolver parte desse projeto.

À Profa. Dra. Marta Ângela Marcondes pela amizade e auxílio para desenvolver esse projeto.

À Claudia Pazini por sua amizade, incentivo e sábios conselhos.

À Roseli Aparecida Candido por sua amizade e torcida.

À Regiane Pires de Campos pelo incentivo, torcida e amizade. 
À Cristiane Soares Pereira pelo apoio, incentivo, torcida, amizade e por tornar possível esse sonho.

Ao Dr. Edson Raddi pelo apoio, incentivo e confiança.

A todos os meus amigos que na jornada da vida se tornaram meus irmãos e que estarão sempre comigo.

Aos meus pais Ester Batista da Silva Candido e Francisco Candido de Assis por sempre acreditarem no meu sonho e estarem lado a lado comigo em todas as etapas.

Aos meus padrinhos Katia Siria Candido da Silva e Eduardo Primo Gomes, pelo apoio, carinho e torcida.

Aos meus irmãos Paulo Alexandre Daniel da Silva, Flavia Cristina da Silva e Eduardo Carlos da Silva Gomes por estarem sempre ao meu lado.

A minha irmã Viviane Vercelone Mota pelo apoio, incentivo, torcida e presença em todos os momentos da minha vida.

A toda a minha família Silva e Araújo por acreditarem, sofrerem comigo e partilhar minhas conquistas.

À minha noiva Jessica Araújo de Paula por fazer essa etapa da minha vida sua etapa também.

Ao CNPq pelo apoio financeiro desse projeto.

Ao projeto FAPESP 10/50547-8 pelo apoio financeiro. 
Os mais sábios são aqueles que tentam e nunca desistem.

Albert Einstein 


\section{RESUMO}

SILVA-NETO, G. M. Avaliação dos parâmetros funcionais e histológicos associados à exposição do peixe beijupirá Rachycentron canadum (Linnaeus, 1766) a concentrações subletais de hidrocarbonetos policíclicos aromáticos (HPAs). 2015. 56 f. Dissertação (Mestrado em Biologia Celular e tecidual) - Instituto de Ciências Biomédicas, Universidade de São Paulo, 2015.

O petróleo é um dos xenobióticos mais utilizados pela humanidade e também um dos mais prejudiciais aos seres vivos. A formação do petróleo é composta em $97 \%$ por hidrocarbonetos, que são os maiores poluentes em potencial. Os hidrocarbonetos policíclicos aromáticos (HPAs), os maiores constituintes do petróleo, são poluentes orgânicos de grande persistência ambiental, e seus compostos derivados são potenciais carcinogênicos que podem afetar toda biota em que estejam envolvidos.

O presente estudo teve como objetivo avaliar os efeitos da exposição subletal aos HPAs na concentração de 0,4 ppm em peixes marinhos da espécie Rachycentron canadum por meio de parâmetros morfométricos, metabólicos e histológicos.

Os HPAs foram obtidos através da extração da fração solúvel de petróleo em água (FSA) e avaliados qualitativamente por meio de espectrometria de fluorescência. Foram avaliados os índices hepato-somáticos (IHS), assim como as possíveis alterações histológicas do tecido hepático dos peixes, supostamente decorrentes da exposição ao xenobiótico. Os parâmetros metabólicos através de biomarcadores de estresse como o cortisol, a glicose e o lactato plasmáticos, assim como a análise complementar por meio das proteínas totais foram determinados.

Os resultados obtidos neste trabalho demonstram que os espécimes de Rachycentron canadum não sofreram alterações nos parâmetros estressores quando submetidos à exposição aos HPAs. Quanto à análise histológica, os animais experimentais apresentaram alterações moderadas a graves no fígado decorrente da exposição aos HPAs. Os beijupirás demonstraram ser bons bioindicadores, por suas características comportamentais e respostas aos parâmetros analisados, o que pode viabilizá-lo como objeto de pesquisa. Cada vez mais, estudos que avaliam o impacto de xenobióticos como os HPAs, os quais em concentrações mínimas em organismos aquáticos podem afetar todo o equilíbrio da biota, evidenciam a importância do monitoramento ambiental, uma vez que a dispersão dos xenobióticos no ambiente pode resultar em mudanças em longo prazo.

Palavras chave: Rachycenton canadum. HPAs. Estresse. Alterações histológicas 


\begin{abstract}
SILVA-NETO, G. M. Evaluation of functional and histological parameters associated to beijupirá Rachycentrun canadum (Linnaeus, 1766) exposure to sublethal concentrations of policyclic aromatic hidrocarbons (PAHs). 2015. $56 \mathrm{f}$. Dissertação (Mestrado em Biologia Celular e tecidual) - Instituto de Ciências Biomédicas, Universidade de São Paulo, 2015.
\end{abstract}

Oil is one of the humanity most used xenobiotics, and also one of the more dangerous to animals. Oil has about $97 \%$ of hydrocarbons in its constitution, which have the major pollutant potential. Polycyclic Aromatic Hidrocarbons (PAHs) are organic pollutants of high environmental persistence level, and its derivatives have carcinogenic potential and can affect all involved biota.

The present study aimed to evaluate the sub lethal exposure effects do $\mathrm{PAH}$ in the marine fish Rachycentron canadum by morphometric, metabolic and histological parameters.

PAHs were obtained by extraction of oil soluble fraction in water (WSA) and were quantitatively evaluated by fluorescence spectrometry. Bioassays were performed using the concentration of $0.4 \mathrm{ppm}$ previously determined. We evaluated the hepatosomatic index (HSI) and the possible histological changes in the liver of the fish, supposedly obtained in consequence of the exposure to the xenobiotic. Metabolic parameters using biomarkers of stress such as cortisol, plasma glucose and lactate, as well as additional analysis by total protein, were determined.

Our results showed that Rachycentron canadum did not show alterations on the parameters of stress. Regarding to the histological analysis, animals presented mild to severe changes in the liver, possibly as result of PAHs exposure. Rachycentron canadum resulted to be a good bioindicator, because of its behavioral characteristics and responses to analyzed parameters, which can make it viable as subject for researches.

Studies that evaluate xenobiotic impacts like PAHs, in which minimal concentrations can affect the equilibrium of all biota, show the importance of environmental monitoring, once environmental xenobiotics dispersion can produce long term changes.

Keys Words: Rachycentron canadum - Stress - PAHs - Histological changes 


\section{LISTA DE ILUSTRAÇÕES}

Figura 1. Reservas mundiais de petróleo - valores confirmados. Fonte Bp, Statistical Review of World Energy, 2013.

Figura 2. Consumo mundial de derivados de petróleo. Fonte Bp, Statistical Review of World Energy, 2013. 19

Figura 3. Divisão da indústria petrolífera. Fonte: Teixeira, F. \& Guerra, O., 2003. 20

Figura 4. Etapas dos processos de exploração e produção offshore. Fonte: Teixeira e Guerra (2003).

Figura 5. Peixe da espécie Rachycentron canadum, utilizados filhotes em todos os bioensaios.

Figura 6. Disposição dos peixes da espécie $R$. canadum durante os bioensaios de exposição subletal aos HPAs na concentração de 0,4 ppm por períodos de 7 e 14 dias.

Figura 7: Fotomicrografia do corte histológico do fígado de Rachycentron canadum, grupo controle. O asterisco indica a presença de um vaso sanguíneo, a seta preta indica hepatócitos formando cordões hepáticos e a seta roxa indica vacuolização citoplasmática. Coloração Hematoxilina - Eosina. Escala $10 \mu \mathrm{m}$.

Figura 8. Análise morfométrica da média dos núcleos de hepatócitos de Rachycentron canadum, indicando o grupo controle e os expostos aos HPAS por 7 e 14 dias na concentração de 0,4 ppm. Foi encontrada diferença estatística entre o grupo controle e os grupos expostos aos HPAs. Anova seguido do teste de Tukey $\left({ }^{*} \mathrm{p}<0,5\right)$

Figura 9. Fotomicrografia do corte histológico do fígado de Rachycentron canadum, grupo exposto a uma concentração de 0,4 ppm de HPAs por 7 dias. O asterisco indica intensa vacuolização citoplasmática. Coloração PAS. Escala $100 \mu \mathrm{m}$. 
Figura 10. Fotomicrografia do corte histológico do fígado de Rachycentron canadum, grupo exposto a uma concentração de $0,4 \mathrm{ppm}$ de HPAS por 14 dias. $\mathrm{O}$ asterisco indica intensa vacuolização citoplasmática; a seta preta indica hiperemia dos vasos hepáticos. Coloração PAS. Escala $100 \mu \mathrm{m}$.

Figura 11. Análise do Índice de Alteração Histológica (I.A.H.) do fígado de Rachycentron canadum, indicando alterações histológicas do grupo controle e dos grupos expostos aos HPAs por 7 e 14 dias na concentração de 0,4ppm. O grupo controle foi classificado com $\mathrm{I}=0$ caracterizando o fígado como normal, o grupo exposto por 7 dias foi classificado com $\mathrm{I}=22$ e o grupo exposto por 14 dias classificado com $\mathrm{I}=23$, caracterizando o fígado de ambos os grupos com alterações moderadas a graves.

Figura 12. Análise do Índice Hepatossomático (I.H.S.) de Rachycentron canadum, indicando os grupos controle e os expostos aos HPAs por 7 e 14 dias na concentração de $0,4 \mathrm{ppm}$. Foi encontrada diferença estatística significativa entre os grupos controle e os expostos aos HPAs. Anova seguido do teste de Tukey $(* \mathrm{p}<5)$

Figura 13. Quantificação da proteína total plasmática de Rachycentron canadum, dos grupos controle e os grupos expostos aos HPAs por 7 e 14 dias na concentração de 0,4ppm. Não houve diferença estatística. Anova seguido do teste de Tukey $(* \mathrm{p}<5)$.

Figura 14. Quantificação dos níveis de cortisol plasmático de Rachycentron canadum, nos grupos controle e os grupos expostos aos HPAs por 7 e 14 dias na concentração de 0,4ppm. Não houve diferença estatística significativa. Anova seguido do teste de Tukey, $(* \mathrm{p}<5)$

Figura 15. Quantificação dos níveis de glicose plasmática Descrição de Rachycentron canadum, nos grupos controle e os grupos 7 e 14 dias na concentração de $0,4 \mathrm{ppm}$. Não houve diferença estatística significativa entre os grupos. Anova seguido do teste de Tukey $(* \mathrm{p}<5)$.

Figura 16. Quantificação dos níveis de lactato plasmático de Rachycentron canadum), nos grupos controle e os grupos expostos aos HPAs por 7 e 14 dias na concentração de 
0,4ppm. Não houve diferença estatística. Anova seguido do teste de Tukey

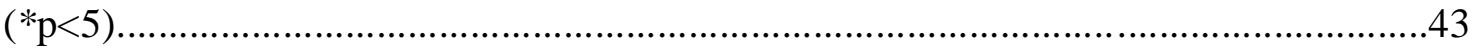




\section{LISTA DE TABELAS}

Tabela 1 Análise de concentrações de HPAs encontradas em diversas áreas de estudo. .24

Tabela2 Alterações histológicas consideradas na análise do fígado para os peixes (Rachycentron canadum) do grupo controle e dos animais expostos aos HPAs (0,3 ppm)

Tabela 3 Relação entre os valores que compõem a fórmula que representa o estágio de alterações devido à contaminação dos HPAs, onde se relaciona I e os efeitos nos órgãos. 


\section{SUMÁRIO}

1 INTRODUÇÃ

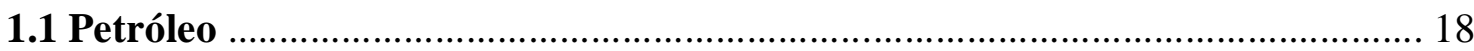

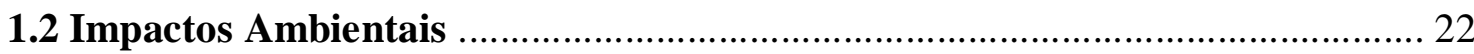

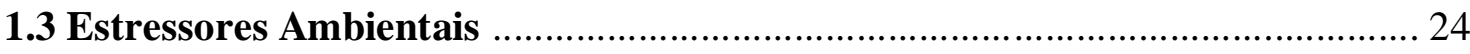

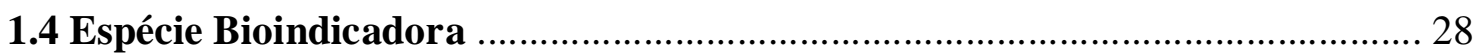

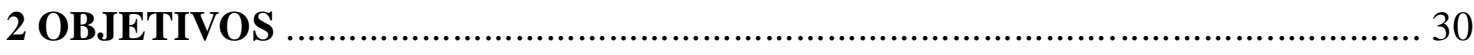

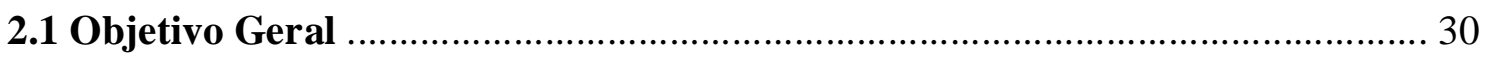

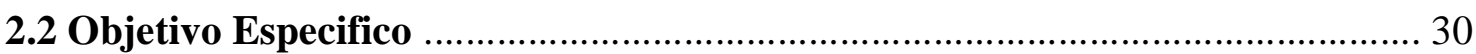

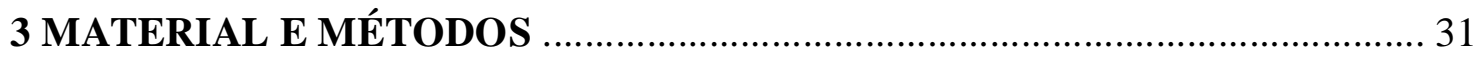

3.1 Extração da Fração Solúvel de Petróleo em Água ......................................... 31

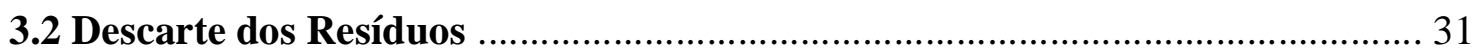

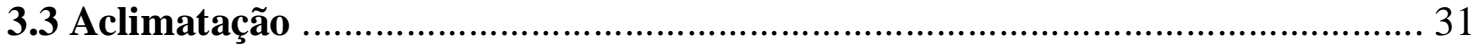

3.4 Determinação da Concentração Letal Média CL50 48 Horas ......................... 32

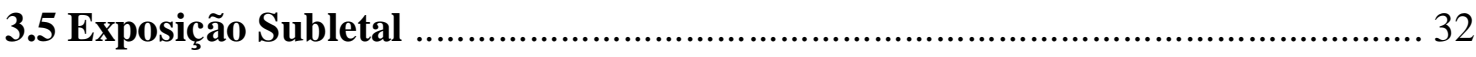

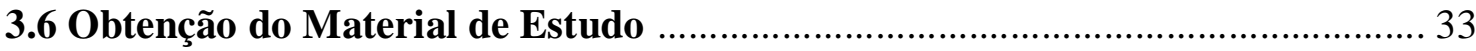

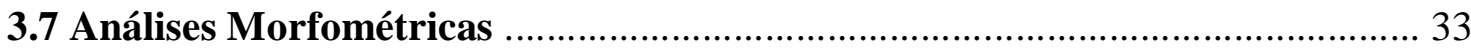

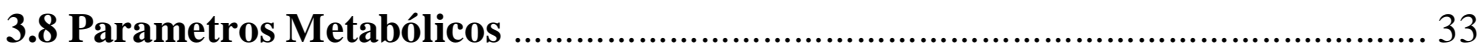

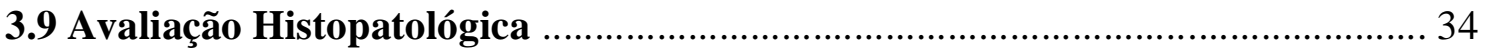

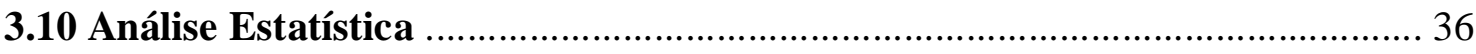

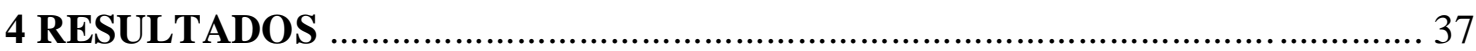

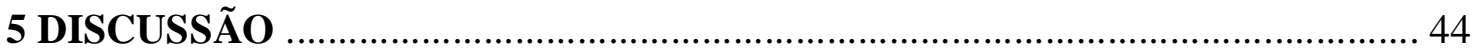


6 CONCLUSÃO

REFERÊNCIAS 


\section{INTRODUÇÃO}

\subsection{Petróleo}

O petróleo (palavra derivada do latim Petra (pedra) + Oleum (óleo)) é um combustível fóssil composto por hidrocarbonetos, compostos nitrogenados, sulfurados, oxigenados e metais pesados. Seus principais hidrocarbonetos são os saturados, insaturados e os aromáticos. Os hidrocarbonetos saturados são constituídos de átomos de carbono, unidos por ligações simples ao maior número possível de átomos de hidrogênio, formando cadeias lineares, ramificadas ou cíclicas. Representam a maior parte da constituição do petróleo líquido e do gás natural. Os hidrocarbonetos insaturados apresentam pelo menos uma ligação dupla ou tripla entre um átomo de carbono e um de hidrogênio. Já os hidrocarbonetos aromáticos são constituídos por ligações alternadas entre duplas e simples formando um anel com seis átomos de carbono, e são subdivididos em: hidrocarbonetos monocíclicos aromáticos que possuem um único anel e são voláteis, cujos hidrocarbonetos mais importantes incluem o benzeno, tolueno, etilbenzeno e xileno (BTEX) e os hidrocarbonetos policíclicos aromáticos (HPA), que possuem dois ou mais anéis aromáticos, como por exemplo: o naftaleno (2anéis); o fenantreno, o antraceno, o fluoreno (3 anéis); o pireno e o benzo(a) antraceno e criseno (4anéis) (ABADIE, 1999; KASSINIS, et al., 1998; ORNELLAS, et al. 2007; SILVA, et al., 2009).

O estado físico do petróleo vai depender da sua formação geológica, local de origem da matéria orgânica e da intensidade do processo térmico. Em estado líquido é uma substância oleosa, inflamável, com cheiro característico, menos denso que a água e com sua coloração variante que pode ser desde o castanho escuro até o negro (ABADIE, 1999).

Para atingir seu nível máximo de aproveitamento, o petróleo deve ser submetido a uma série de processos que são conhecidos como refinamento. Ao passar pelo refinamento, ele recebe uma série de beneficiamentos que englobam etapas físicas, químicas e de separação, que originam as frações de destilação. Estas são processadas por meio da separação e da conversão para então atingir seus derivados finais (ABADIE, 1999; SILVA, et al., 2009).

A indústria do petróleo por volta do ano de 2000 desencadeou uma preocupação com o esgotamento das reservas de petróleo confirmadas até então (figura 1), preocupação essa que foi intensificada pelo aumento da demanda de petróleo utilizada 
(figura 2), e como solução voltou sua atenção para a exploração offshore. Isso fez com que o avanço tecnológico que abrange desde a exploração de águas profundas e ultraprofundas, como o aperfeiçoamento dos meios de transporte, as novas fontes de energia assim como o processo de refinamento, fossem muito intensificados (FINNVEDEN, et al., 2002).

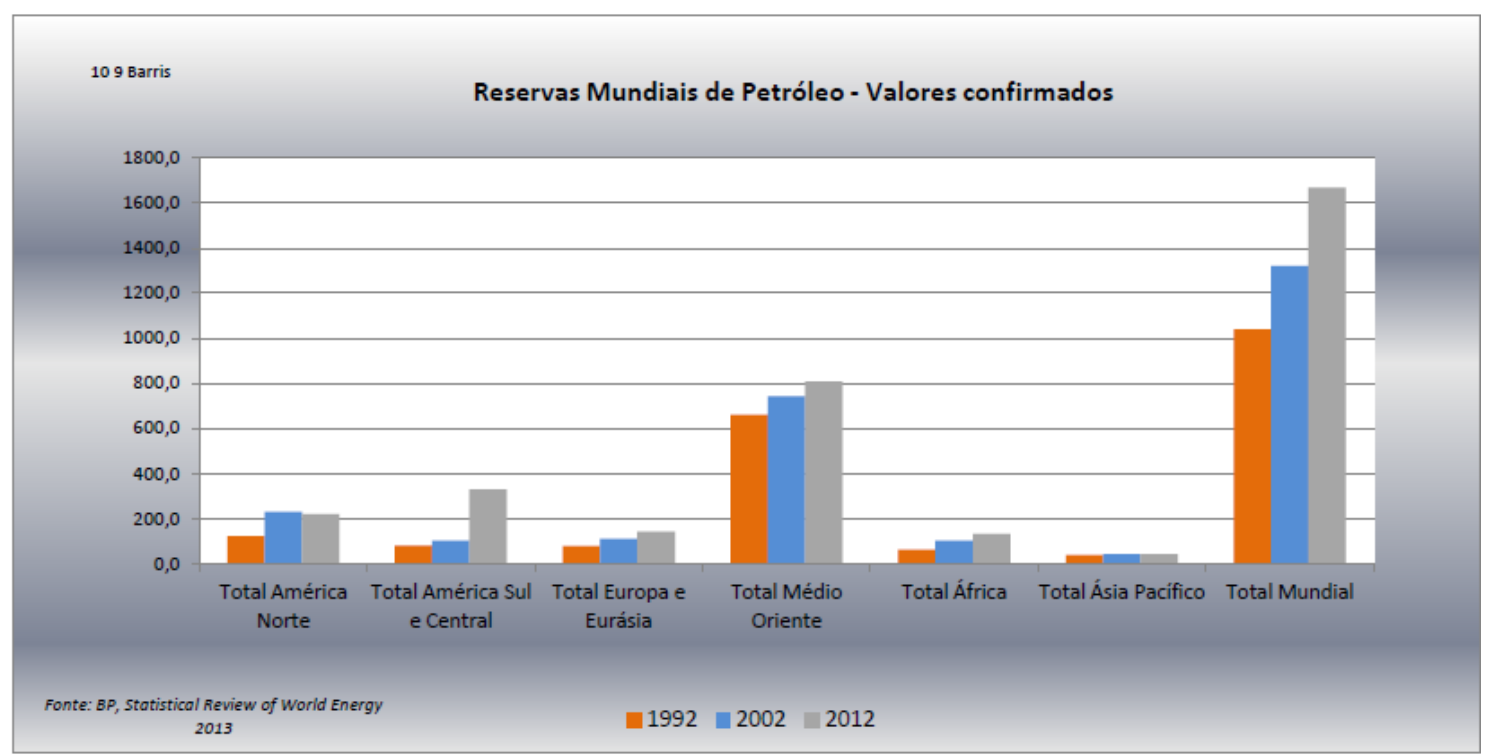

Figura1. Reservas mundiais de petróleo - valores confirmados. Fonte Bp, Statistical Review of World Energy, 2013.

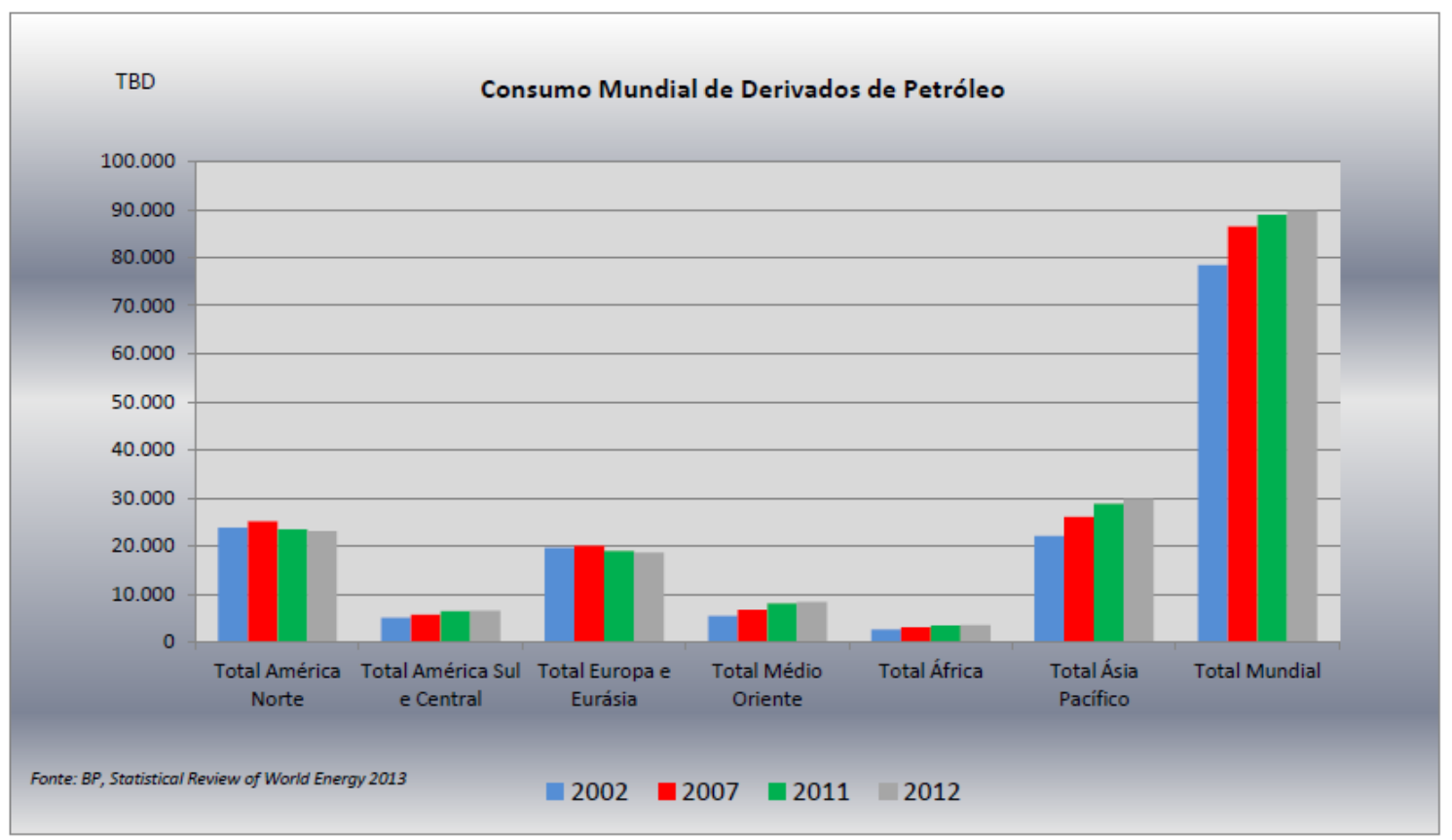

Figura 2. Consumo mundial de derivados de petróleo. Fonte Bp, Statistical Review of World Energy, 2013. 
Uma indústria petrolífera se divide em dois grandes blocos que envolvem atividades distintas, o primeiro é chamado de upstream que é o responsável pelas atividades relacionadas à exploração e produção do petróleo, o segundo bloco é chamado de downstream e está relacionado ao transporte, refino e distribuição do composto (figura 3) (TEIXEIRA; GUERRA, 2003).

Upstream

Downstream

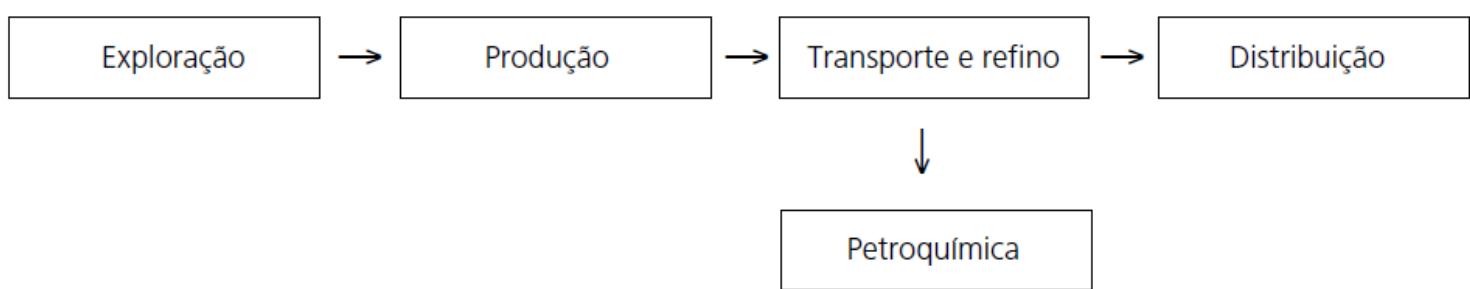

Figura 3. Divisão da indústria petrolífera. Fonte: Teixeira e Guerra, 2003.

De acordo com Teixeira e Guerra (2003), para se iniciar uma exploração offshore são necessárias cinco etapas que envolvem exploração, reservatório, perfuração, completação e produção. Os itens que compõem essas etapas estão descritos na figura 4. 
Exploraçăo

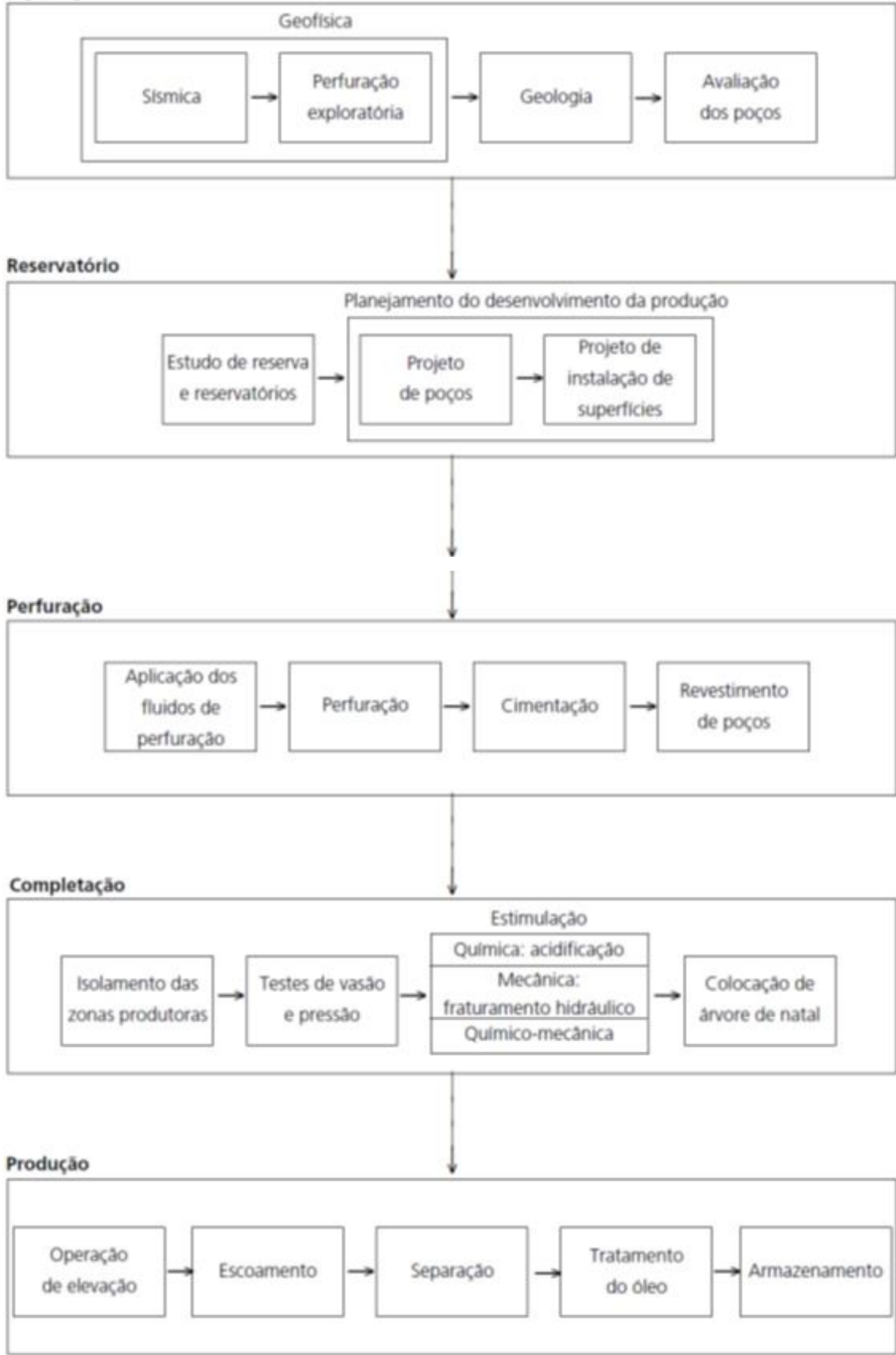

Figura 4. Etapas dos processos de exploração e produção offshore. Fonte: Teixeira e Guerra (2003). 


\subsection{Impactos ambientais}

O ambiente aquático é invariavelmente atingido pela ação antrópica, seja de forma direta ou indireta, afetando o desenvolvimento de toda a biota local. Pesquisas com o intuito de avaliar os efeitos dos poluentes ambientais em peixes têm mostrado que a ação desses fatores está afetando esses animais, e a toxicidade dos xenobióticos vem alterando: taxas no aumento da ventilação branquial dos peixes; aumento da captação de substâncias tóxicas exógenas e a sinergia existente entre as mesmas (ALCARAZ; ESPINA, 1995; KOCK, et al., 1996; MACLEOD; PESSAH, 1973; SILVA, et. al., 2002). Todos esses efeitos podem tornar o potencial de produtividade mais baixo alterando tanto as populações de peixes selvagens como em sistemas de aquicultura intensiva que é praticada em vários países (WINKALER, et al., 2001; ZANIBONI; WEINGARTNER, 2007).

Tratando-se especificamente do petróleo, o risco de contaminação no meio ambiente é iminente desde o início de sua obtenção, nos processos de prospecção, extração e refino, até seu destino final (NISHIGIMA, et al., 2001; SILVA et al., 2009). As atividades relacionadas com a exploração de petróleo são potenciais geradores de impactos ambientais: estima-se que de 1970 a 2005 foram lançados cerca de 5.700.000 toneladas de óleo no mar (CANTAGALLO, et al., 2007).

A contaminação aquática por petróleo pode ocorrer por meio de acidentes que envolvam grandes quantidades como o ocorrido em 1989 no Alasca (E.U.A) com o petroleiro Exxon Valdez; em Angola no ano de 1991; no Litoral norte no Canal de São Sebastião em 1978 e no Golfo do México em 2010. Esses acidentes comumente tornamse irreversíveis, devido à sua alta toxicidade e volume. Também através de pequenas quantidades, que podem ocorrer por um longo período de forma silenciosa, através das atividades rotineiras, seja por falta de manutenção ou mesmo de investimentos em segurança ambiental (TIBURTIUS; ZAMORA, 2004).

Os contaminantes ambientais que entram em contato com o ecossistema marinho podem prejudicar em vários aspectos a homeostase desses organismos aquáticos (SILVA et al., 2009).

Com a contaminação, da água pode ocorrer diversas alterações nos organismos aquáticos. No caso dos peixes, a contaminação crônica subletal pode causar ao longo do tempo: supressão do sistema imune; alterações no sistema endócrino; inibição ou falha reprodutiva; lesões teciduais; efeitos teratogênicos e danos no DNA. 
Hoje encontramos muitas áreas com problemas de contaminação por petróleo e a médio e longo prazo isso vem se tornando um fator preocupante. Informações que demonstrem de que forma esse composto está afetando o meio ambiente torna-se cada vez mais relevantes (ASS, et al., 2001; BERNET, et al.,1999).

De acordo com Tiburtius e Zamora (2004) o potencial carcinogênico dos HPAs deve ser muito bem avaliado para se ter um parâmetro dos riscos e dos efeitos que os organismos estão expostos.

No caso dos peixes que possuem total interação com meio aquático, a contaminação pode custar uma adaptação além dos seus limites, levando o indivíduo a mudanças que possam acarretar danos irreversíveis (ALCARAZ; ESPINA, 1995; KOCK, et al., 1996; MACLEOD; PESSAH, 1973; SILVA et al., 2002; WINKALER, et al., 2001; ZANIBONI; WEINGARTNER, 2007).

Quando os animais aquáticos são afetados pelos contaminantes ambientais, o fígado, que é um órgão central com inúmeras funções vitais no metabolismo básico dos vertebrados e que é o principal sítio de biotransformação da maioria dos xenobióticos, que estão presentes no ambiente aquático, torna possível a detoxificação ou a bioativação dessas substâncias, que pode levar o animal a uma adaptação que nem sempre lhe é favorável (PEREIRA; MARTINEZ, 2007; SANTOS, et al., 2004).

Para identificar como os animais estão sendo afetados, são utilizadas espécies que sejam bioindicadoras, pois elas possuem todos os atributos necessários para identificar os danos que tanto este xenobiótico como outros causam no meio que estes animais vivem (BEG, et al., 2009; KENNISH, 1997; TIBURTIUS; ZAMORA, 2004).

É sabido que os HPAs se destacam por sua estabilidade e persistência no meio aquático, levando os animais a níveis de estresse que podem ultrapassar os seus limites, tornando-os mais suscetíveis a doenças, predadores, mutações e outras condições prejudiciais que podem levar as espécies mais sensíveis a extinção (WINKALER, et al., 2001; ZANIBONI; WEINGARTNER, 2007).

De acordo com Rangel et al. (2012) as concentrações de HPAs em diversas áreas de estudos, demostram que esse xenobiótico está cada vez mais presente no meio aquático (tabela 1), e com isso a dinâmica natural desse ambiente pode ser alterada e assim afetar todos os seres que nele habitam. 
Tabela 1 Análise de concentrações de HPAs encontradas em diversas áreas de estudo.

\begin{tabular}{lcl}
\hline \multicolumn{1}{c}{ Area de amostragem } & Concentrações (mg/kg) & Autores \\
\hline Bacia do Rio Estrela & $0,00-0,09$ & Este estudo \\
Baía de Guanabara & $1,57-18,44$ & Lima (1996) \\
Baia de Guanabara & $0,0-0,01$ & Meniconi \& Gabardo ( 2002) \\
APA de Guapimirim (Baía de Guanabara) & $0,3-42,7$ & Botelho (2003) \\
Bacia de Tianjin- China & $0,01-0,5$ & Shi et al., (2005) \\
Canal de Saint John, Louisiana-USA & $0,12-78,73$ & Nowat \& Bundy (2001) \\
Canal Trepagnier, Louisiana -USA & $0,49-25,64$ & Nowat \& Bundy (2001) \\
Bacia do Rio Paraiba do Sul/Guandu & $1-40$ & Torres et al., (2002) \\
Delta do Niger, Nigéria & $2,1-7,2$ & Olajire et al., (2005) \\
\hline
\end{tabular}

Fonte: Rangel et al., 2012.

\subsection{Estressores Ambientais}

O ambiente aquático é extremamente dinâmico e proporciona aos organismos que nele habita a ação de inúmeras alterações como, por exemplo: mudanças rápidas na concentração de $\mathrm{O}_{2}$ dissolvido, no $\mathrm{pH}$, e na salinidade. Além disso, os estressores ambientais químicos como os HPAs vêm exigindo dos peixes, que tem uma grande interação com este ambiente, uma adaptação. Contudo isso pode alterar de forma negativa o delicado equilíbrio que existe entre esses animais e seus habitats, e também provocar mudanças em seus organismos (BARTON et al., 1991; COSTA, et al., 2005; WESTER, et al., 2002).

Os fatores de estresse tem sido a principal causa das perdas de lucros na piscicultura, pois afetam o metabolismo e consequentemente a reprodução e o crescimento dos peixes (LIMA, et al., 2006).

O estresse pode ser descrito como um estímulo que promove alterações na homeostase, envolvendo o sistema nervoso autônomo. Alguns autores consideram o estresse como uma série de respostas, denominada como Síndrome Geral de Adaptação, a qual apresenta três estágios: primeiro a reação de alarme, onde ocorre uma série de alterações fisiológicas como resposta inicial ao estímulo, a fim de compensar o distúrbio; segundo a resistência, através de respostas fisiológicas de ajuste ou compensatórias para retorno à homeostase e por último a exaustão, onde a duração ou severidade dos distúrbios causados pela exposição ao estressor excede os limites, podendo levar a uma condição patológica ou morte (LIMA et al., 2006).

Martins da Rocha e colaboradores (2004) descrevem o estresse como um estado produzido pelo ambiente ou outro fator, que promove respostas adaptativas além da faixa normal de funcionamento do organismo, de modo que as chances de sobrevivência 
tornam-se significativamente reduzidas. Sendo assim a resposta ao estresse é uma forma de adaptação que melhora as chances de sobrevivência frente a uma situação que exponha o animal a uma condição fora de seu padrão normal.

De acordo com Brandão e colaboradores (2006), as respostas de estresse podem ser divididas em três categorias: primária, secundária e terciária. As respostas primárias são as hormonais, as secundárias são mudanças nos parâmetros fisiológicos e bioquímicos e as terciárias são o comprometimento no desempenho, mudanças no comportamento e aumento da suscetibilidade a doenças.

Em situações de estresse, o cortisol tem seu nível elevado e atua no metabolismo dos carboidratos, gorduras e proteínas, e possui três ações primarias: estimular a quebra de proteínas, de gorduras, e providenciar a metabolização da glicose no fígado (ALURU; VIJAIAN, 2009; CARRIÓN, et al., MARTINS DA ROCHA et al., 2006; VIJAYAN, et al., 2003). É conhecido como o hormônio do estresse, pois ativa respostas do corpo diante de situações de emergência, onde aumenta a pressão arterial e o açúcar no sangue, gerando energia muscular. Ao mesmo tempo, todas as funções anabólicas de recuperação, renovação e criação de tecidos são paralisadas e o organismo se concentra na sua função catabólica para a obtenção de energia. Uma vez que o estresse é superado, os níveis hormonais e o processo fisiológico voltam à normalidade, mas quando este se prolonga, os níveis de cortisol no organismo disparam (BRANDÃO, et al., 2006). O figado é um órgão alvo do cortisol, pois reflete suas principais ações, como o metabolismo energético e outras, como a reduçaõ do crescimento, falha no sistema imune e reprodutivo (WENDELAAR BONGA, 1997).

De acordo com Aluru e Vijayan (2009) uma das respostas ao estresse é a rápida elevação do nível de cortisol no plasma sanguíneo. O cortisol que é um hormônio corticosteróide, que também é responsável pela diferenciação das células de cloreto, as quais têm como uma das funções principais a osmorregulação em animais marinhos. Este hormônio apresenta também efeitos sobre o metabolismo de carboidratos, proteínas e lipídeos. A resposta ao estresse geralmente é seguida por hiperglicemia, devido á ação do cortisol sobre a glicose hepática através da gliconeogênese, proporcionando uma energia extra para que o animal tenha forças para superar situações que envolvam mudanças, sendo elas físicas ou fisiológicas.

De acordo com Aluru e Vijayan (2009), os efeitos do cortisol podem ser diretos, quando ocorre o aumento da produção de glicose, e indiretos, aumentando a ação dos hepatócitos, da adrenalina e da insulina sobre o metabolismo dos carboidratos. 
O cortisol é considerado um ótimo indicador para avaliação de estresse primário em peixes (MOMMSEN, et al., 1999). Seus resultados podem ser facilmente comparados com o de outras espécies, pois existe uma vasta literatura sobre este bioindicador (BARTON, et al., 2002).

Para avaliação da resposta secundária, temos a determinação da concentração dos níveis de glicose sanguínea ou plasmática. Assim como nos mamíferos, a glicose para os peixes é a principal fonte de energia, e quando esta não é suficiente para manter a homeostase do animal, outra fonte energética proveniente do fígado é disponibilizada, o glicogênio (MOMMSEN et.al., 1999; SILVEIRA, et al., 2009; TIHONEM, et al., 1995).

De acordo com Aluru e Vijayan (2007), a glicose durante o período de estresse é produzida pelo fígado por gliconeogênese, que converte o glicogênio em glicose, com o intuito de levar energia para outros tecidos além do fígado, como o cérebro, brânquias e coração. Quando o organismo do animal utiliza essas vias, ocorre sinalização adrenérgica e ativação da via glicogeneolitica, e a manutenção em longo prazo nos níveis de glicose, assim como a reposição do conteúdo de glicogênio hepático, está associado á alta regulação das vias gliconeogênicas (WISEMAN, et al., 2007).

De acordo com Vijayan (2003), a glicose é comumente usada como parâmetro indireto de estresse nos peixes, mas sua resposta é dependente de outros fatores, tais como o cortisol e o lactato plasmático.

A utilização dos medidores de glicose é de simples utilização e facilmente encontrados no mercado, sendo amplamente utilizado para respostas relacionadas ao estresse (SILVEIRA, et al., 2009).

O lactato também é um ótimo indicador para respostas secundarias, e de acordo com Randall e Perry (1992), os níveis de lactato são aumentados quando o peixe sofre um estresse agudo como o manejo, a captura e até mesmo hipoxia. Ele é produzido após a queima da glicose (glicólise), sendo o produto final dessa degradação (metabolismo anaeróbico láctico), onde o corpo encontra uma fonte de energia sem a presença de oxigênio. Também pode ser gerado através de tecidos bem oxigenados pela glicólise aeróbica. É uma substância dinâmica e quando produzida tem a tendência a sair do músculo entrando nos músculos vizinhos e na corrente sanguínea ou até mesmo no espaço entre as células musculares. É produzido diariamente pelo corpo em baixa quantidade. Quando existe o aumento de atividade ocorre o aumento do piruvato, e como o organismo não consegue utilizá-lo totalmente como energia aeróbia, ele acaba 
sendo transformado em lactato. Ao ser captado pelo fígado é convertido em glicose através da gliconeogênese, ou utilizado como energia.

A glicose em sua forma anaeróbica produz $47 \mathrm{kcal} / \mathrm{mmol}$, e na sua forma aeróbica produz $673 \mathrm{kcal} / \mathrm{mmol}$; a oxidação do lactato produz $326 \mathrm{kcal} / \mathrm{mmol}$, um mole de glicose gera 2 moles de lactato; com isso a energia gerada pelo lactato pode ser utilizada em outros órgãos que ainda estejam em aerobiose como o sistema nervoso central. O lactato pode ser classificado como uma fonte de energia alternativa do organismo.

O lactato em grande concentração no organismo pode gerar hiperacidez, que indiretamente determina uma acidose metabólica, e através dele podemos medir o acúmulo de ácido láctico decorrente do aumento do exercício físico à medida que os animais são expostos a um agente estressor (NELSON; COX, 2011; SILVEIRA, et al., 2009).

Para a resposta terciária temos a avaliação histológica de órgãos, sendo os mais utilizados as brânquias e o fígado. A ocorrência de alterações celulares e teciduais decorrentes da exposição a estressores ambientais como PCBs, HPAs, organoclorados, organofosforados, metais pesados, dentre outros, têm sido relatadas por vários autores (OLIVEIRA RIBEIRO, et al., 2000; SALVO, et al., 2008). Estudos tratando especificamente dos efeitos dos HPAs em organismos aquáticos demonstraram que peixes expostos a esses xenobióticos num derramamento de petróleo apresentam sérias alterações no epitélio branquial, com lesões estruturais nas lamelas respiratórias e hiperplasia de células secretoras e de cloreto, comprometendo assim as trocas gasosas dos mesmos com o meio, resultando em hipóxia (BARTON, et al., 1991; BARTON, et al., 2002; PRASAD, 1991).

Como analise complementar a resposta terciaria, um ótimo indicador são as proteínas totais. Constituídas basicamente pela albumina e globulinas, constituem a parte estrutural da maior parte dos órgãos. Além disso, atuam como catalisadores enzimáticos nas reações bioquímicas, como carreadores de muitos constituintes do plasma e da defesa do organismo. A albumina é uma lipoproteína transportadora de moléculas pequenas e sua função é evitar perda de liquido dos vasos sanguíneos através da pressão osmótica; sua síntese é influenciada pela nutrição, balanço hormonal, estado geral do fígado e estresse. As globulinas abrangem proteínas que atuam no sistema imune, enzimas e proteínas transportadoras (KANEKO, 1997; LEITE, 1995). 
O estresse exerce efeito depressivo sobre várias respostas imunológicas em peixes, como o aumento nas proteínas totais, na diminuição de anticorpos e no número de células produtoras de anticorpos (CARLSON, et al., 1993; MILLIGAM; WOOD, 1982).

De acordo com Barros (2006), a avaliação de parâmetros sanguíneos como a determinação dos níveis de proteína total é eficaz na análise complementar de medidores do estresse, ocasionados por alterações fisiológicas seguidas de condições de estresse, sendo essa nutricional, física ou química.

Com a quantificação de proteínas totais, pode-se determinar se existe alguma anormalidade ocorrendo com o indivíduo, onde quando as proteínas estão em níveis elevados, pode representar uma doença crônica do fígado, e quando em níveis baixos, pode ser resultado de uma insuficiência do fígado e doença renal (RANZANI PAIVA; SILVA-SOUZA, 2004).

\subsection{Espécie Bioindicadora}

O Rachycentron canadum, único representante da família Rachycentridae, é uma espécie de peixe marinho nativa, popularmente conhecido como beijupirá (peixe da pele amarela em tupi-guarani), e por vários outros nomes de acordo com a região em que se encontra, como por exemplo, parambiju e cobia (BENNETI, et al., 2008; CAVALLI, et al., 2009; SANCHES et al., 2008). Devido à excelente qualidade de sua carne e sua fácil adaptabilidade em cativeiro possui alto valor comercial. É uma espécie nerítica e epipelágica de hábito natatório ativo devido à ausência de bexiga natatória e de comportamento migratório. Prefere águas mais quentes, na qual a temperatura média é de $24{ }^{\circ} \mathrm{C}$ e sua ocorrência se dá em áreas do oceano Atlântico e do Pacífico. No Brasil está presente nas regiões norte, nordeste, sul e sudeste (ARENDT et al., 2001; CAVALLI, et al., 2009).

O Rachycentron canadum é um animal de crescimento rápido podendo atingir o peso de $23 \mathrm{~kg}$ e comprimento de até dois metros. Seu corpo é alongado em forma de torpedo, possui a cabeça chata e a mandíbula inferior projetada para frente sendo facilmente distinguido pela primeira nadadeira dorsal, que é composta de 7 a 9 curtos e fortes espinhos isolados, não ligados por membrana. A nadadeira caudal é semilunar em adultos e em forma de remo nos jovens. Suas escamas são pequenas e encaixadas na pele. Possuem bandas de dentes nas maxilas e na região do palato e da língua. A coloração nos adultos varia entre marrom e bronze, sendo a parte ventral creme com 
duas faixas laterais que variam do branco ao bronze, os jovens possuem um branco mais nítido e um toque de rosa na nadadeira caudal. Sua maturidade sexual geralmente é atingida a partir do segundo ano de vida (BENNETI, et al., 2008; FAULK, et al., 2007; SANCHES et al., 2008).

Em geral essa espécie vive isolada juntando-se aos outros apenas para realizar a desova. É uma espécie carnívora alimentando-se de nécton e zoobentos, incluindo peixes, crustáceos, bivalves e podem também seguir grandes animais como tubarões, tartarugas e raias manta para obter restos de presas que são deixados para trás. Esse animal pode associar-se a estruturas que estejam na água (boias, lixos, naufrágios, recifes artificiais e outros elementos estruturais), e também conseguem adentrar em estuários e manguezais em busca de presas. Devido à sua alta adaptabilidade em busca de alimento e também de locais em que pode ocorrer, o beijupirá ocupa uma posição de destaque na cadeia trófica, tornando-o um bom objeto de pesquisa, pois devido a essas características pode-se correlacioná-lo diretamente ao ecossistema em que vive (BENNETI, et al., 2008; CAVALLI, 2009). 


\section{OBJETIVOS}

\subsection{Objetivo Geral}

Avaliar os efeitos subletais da fração solúvel de petróleo (FSA) em peixes marinhos da espécie Rachycentron canadum (Linnaeus, 1766), por meio de parâmetros morfométricos, metabólicos e histológicos.

\subsection{Objetivos Específicos}

Para os peixes da espécie Rachycentron canadum após os diferentes tratamentos com HPAs na concentração de 0,4 ppm:

Exposição subletal por um período de 7 e 14 dias;

Avaliar os peixes quanto aos parâmetros morfométricos;

- Determinar o índice hepatossomático e fator de condição;

- Caracterizar o tecido hepático quanto à estrutura morfológica e avaliar as possíveis alterações celulares por meio de técnicas histológicas;

- Determinar os níveis de cortisol, glicose e lactato plasmáticos assim como quantificar as proteínas totais. 


\section{MATERIAL E MÉTODOS}

\subsection{Extração da Fração Solúvel de Petróleo em Água}

Amostras de petróleo previamente caracterizadas química e fisicamente foram requisitadas ao centro petroquímico da Petrobrás do município de São Sebastião -SP TEBAR. A fração solúvel foi obtida conforme o método de Vieira (2009), sendo a curva de saturação na subfase aquosa obtida pela monitoração da fluorescência em intervalos de tempos apropriados que foram determinados para a amostra fornecida pela Petrobrás. O protocolo de extração tem sido amplamente utilizado e foi pré-estabelecido por Lee e Anderson (2005) e adaptado em nosso laboratório (SALVO, et al., 2012). As análises foram realizadas no Instituto de Química da Universidade de São Paulo em espectro fluorímetro Shimadzu RF-5301PC.

\subsection{Descarte dos Resíduos}

Ao término de cada experimento, as águas dos aquários foram coletadas, e acondicionadas em recipientes plásticos de 1.000 litros. Posteriormente, os mesmos foram enviados a Petrobrás para tratamento e disposição final dos resíduos, de acordo com a Resolução do CONAMA n. ${ }^{\circ} 358 / 2005$.

\subsection{Aclimatação}

Espécimes de Rachycentron canadum (Linnaeus, 1776) (figura 5), totalizando 60 indivíduos com comprimento total de $23,18 \mathrm{~cm}( \pm 1,75)$, comprimento médio padrão de $18,56 \mathrm{~cm}( \pm 1,69)$ e média de peso de $52,26 \mathrm{~g}( \pm 3,77)$, foram obtidos na estação de piscicultura ME localizada no Litoral Norte de São Paulo em Ilha Bela. Uma parte dos experimentos foi realizada no Centro de Biologia Marinha da USP (CEBIMar/USP) e outra parte no biotério aquático do laboratório de Histofisiologia Evolutiva do Instituto de Ciências Biomédicas da USP (ICB/USP). Os beijupirás foram acondicionados em aquários de 150 litros, sob condições abióticas controladas diariamente quanto: ao pH $(8 \pm 0,2)$; o fotoperíodo natural; a temperatura $\left(23 \pm 2{ }^{\circ} \mathrm{C}\right)$; a salinidade $(34 \pm 2 \%$; o oxigênio dissolvido e a concentração de amônia. O alimento fresco foi fornecido $a d$ 
libitum uma vez ao dia. Nessas condições, os peixes passaram por um período de aclimatação de 15 dias para diminuição do estresse.

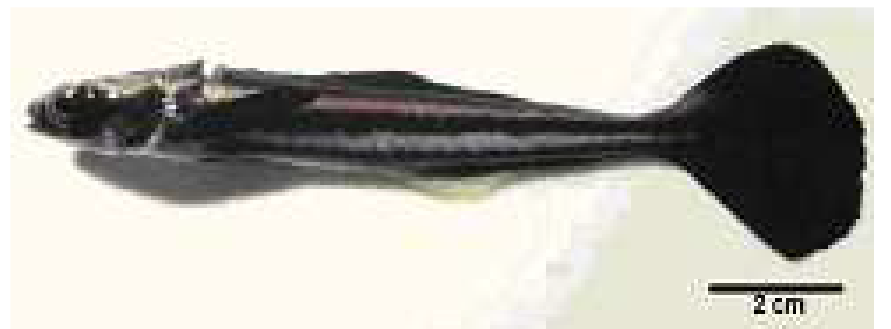

Figura 5. Peixe da espécie Rachycentron canadum, utilizados filhotes em todos os bioensaios.

\subsection{Determinação da Concentração Letal Média $\left(\mathrm{CL}_{50}\right) 96$ Horas}

A concentração letal média $\left(\mathrm{CL}_{50}\right)$ da fração solúvel em água (FSA) em 96 horas de exposição foi previamente determinada por Salvo et al., 2012, e ficou estabelecida em 0.6 ppm.

\subsection{Exposição Subletal}

Os bioensaios foram realizados utilizando a concentração de 0.4 ppm e para isso, os beijupirás foram divididos em três grupos de dez indivíduos cada, sendo um grupo controle e dois grupos experimentais. Um grupo foi exposto à FSA na concentração de 0,3 ppm por um período de 7 dias, e o outro grupo por um período de 14 dias. O sistema utilizado foi o semi-estático, o qual permite a renovação parcial da água do mar a cada 48 horas (figura 6). Os aquários tinham a capacidade de $150 \mathrm{~L}$ cada e nos mesmos foram colocados a proporção equivalente a menos de 1 grama de peixe por litro de água, evitando assim o estresse.

As condições abióticas foram semelhantes às descritas no item 3.3 com exceção da alimentação, a qual foi fornecida normalmente até 24 horas antes do término dos experimentos, quando foi interrompida e os peixes mantidos em jejum. 


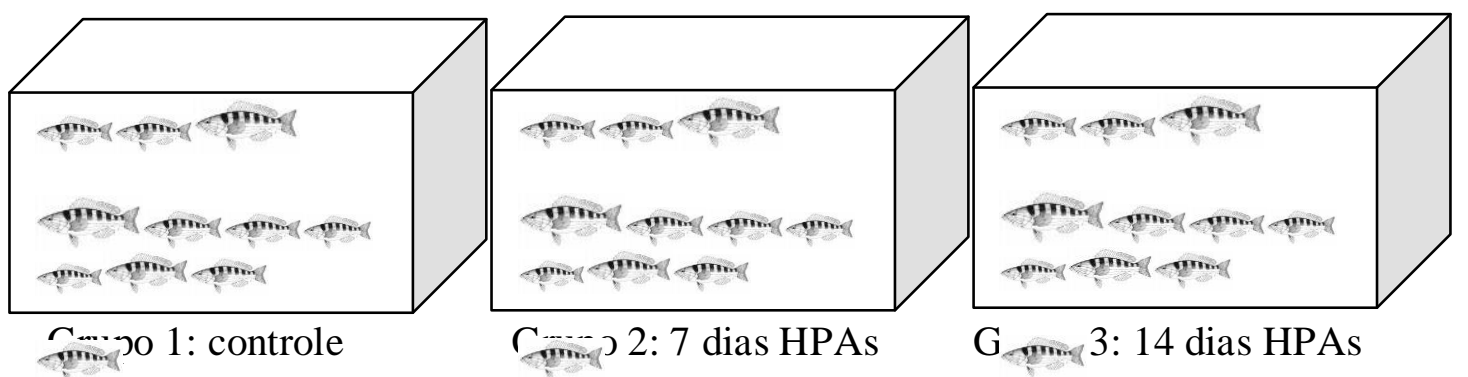

Figura 6. Disposição dos peixes da espécie $R$. canadum durante os bioensaios de exposição subletal aos HPAs na concentração de 0,4 ppm por períodos de 7 e 14 dias.

\subsection{Obtenção do Material de Estudo}

Após os períodos de 7 e 14 dias de exposição subletal á FSA, os peixes de todos os grupos foram anestesiados com benzocaína $2 \%$, tiveram o sangue puncionado da veia caudal por meio de seringas heparinizadas. Para obtenção do plasma, o sangue foi centrifugado através do equipamento Hettich Zentrifugen com RPM 3000, RAD/mm 100, RCF 1006 por 3 minutos. Para o processamento histológico, os peixes foram eutanasiados após secção medular e tiveram o fígado retirado e pesado. Posteriormente os fígados foram seccionados em pequenos fragmentos de aproximadamente $3 \mathrm{~cm}$, fixados em solução de Mcdowell gelado (paraformaldeído 4\% e glutaraldeído $25 \%$ em tampão fosfato - $\mathrm{pH} 7.2$ ) por um período de 24 horas.

\subsection{Análises Morfométricas}

Os fígados colhidos foram pesados e os índices somáticos calculados segundo Adams e Maclean (1985), de acordo com a seguinte equação:

Índice hepatossomático: IHS $=($ Peso fígado/ Peso peixe $)] \times 100$.

Fator de condição: $\mathrm{FC}=\left(\right.$ Peso de peixe/Comprimento total $\left.{ }^{3}\right) \times 100$.

Fórmulas de acordo com Bagenal e Tesch, (1978).

\subsection{Parâmetros Metabólicos}

Foram avaliados os parâmetros influenciados pelos agentes estressores. O material colhido foi centrifugado durante três minutos para analisar o cortisol através de ensaios enzimáticos e leitura realizada por meio do equipamento ELISA, assim como a glicose 
que foi analisada em ensaio por kits enzimáticos colorimétricos e leitura realizada através do equipamento ELISA; lactato realizado através de análise quantitativa por meio do kit IDEXX Vettest e sua leitura feita pelo equipamento Vet Test 8008: esse teste é de comum utilização, inclusive em peixes, e por meio dele podemos quantificar o material analisado e detectar de maneira simples e eficaz alterações no material. (FERREIRA, et al., 2010).

Parâmetros complementares também foram analisados, como a análise da proteína total para avaliar o nível de comprometimento ao qual o estresse levou esse animal. Adicionalmente, essas análises também foram efetuadas por meio de kit IDEXX Vet Test e a leitura realizada através do equipamento Vet Test 8008.

\subsection{Avaliação Histopatológica}

Os fígados fixados em Mcdowell foram desidratados em álcool e incluídos em Paraplast $($ Sigma $@$ ). Posteriormente, foram realizados cortes de $4 \mu \mathrm{m}$ no micrótomo Zeiss ${ }^{\circledR}$ Hyrax M25, as lâminas foram preparadas e coradas com ácido periódico - Schiff (PAS) e Hematoxilina- Eosina (HE).

As lâminas prontas foram digitalizadas utilizando o microscópio com câmera AxioCam HRC (Zeiss), onde foram tiradas 10 fotos de 5 cortes diferentes de cada peixe totalizando em 50 fotos nos aumentos finais de 1000x, 400x e 100x. Após a digitalização das lâminas, os cortes de fígado foram submetidos a um programa específico de mensurações de área, Image $\mathbf{J}^{\circledR}$.

Nos cortes foram analisadas 100 áreas, medindo o núcleo dos hepatócitos e fazendo a contagem dos vasos sanguíneos.

Também foi analisada a presença de alterações histológicas nos fígados, e as mesmas classificadas em estágio de severidade segundo o método de Poleksic e Mitrovic-Tutundzic (1994). Esse método classifica em estágios (I, II, e III) o grau de danos encontrado no material analisado (tabelas 1 e 2). 
Tabela 2 Alterações histológicas consideradas na análise dos fígados dos peixes (Rachycentron canadum) do grupo controle e dos animais expostos aos HPAs $(0,4 \mathrm{ppm})$

\begin{tabular}{ll}
\hline Alteracões Histológicas Hepáticas & Estágio \\
\hline \hline a) Alterações nos hepatócitos & \\
\hline Desarranjo dos cordões hepáticos & I \\
Perda ou atipia do contorno celular & I \\
Perda ou atipia do contorno nuclear & I \\
Aumento do volume celular & I \\
Aumento do volume nuclear & I \\
Atrofia nuclear & II \\
Intensa vacuolização citoplasmática & I \\
Vacuolização nuclear & II \\
Diminuição da freqüência relativa de ocorrência de & I \\
Degeneração citoplasmática & II \\
Degeneração nuclear & II \\
Rompimento celular & II \\
Diminuição do glicogênio & I \\
Estagnação biliar & I \\
\hline b) Alterações nos vasos sanguíneos & \\
\hline Aumento da frequência relativa de vasos sanguíneos & I \\
Hiperemia & II \\
Ruptura de vasos & II \\
Aumento do volume relativo dos vasos & I \\
\hline c) Alterações nos canalículos biliares & II \\
\hline Degeneração dos canalículos biliares & \\
\hline d) Estágio terminal & III \\
\hline Necrose (focal ou total) & \\
\hline
\end{tabular}

Após a análise das alterações, foi utilizado o Índice de Alteração Histológica (I.A.H.) por intermédio de uma equação que permite quantificar essas alterações, tornando possível comparar o grau de alteração encontrado e correlacionar os dados encontrados com o estresse em que o peixe está envolvido:

$$
\begin{array}{ccr}
\mathrm{na} & \mathrm{nb} & \mathrm{nc} \\
\mathrm{i}=1 & \mathrm{i}=1 & \mathrm{i}=1
\end{array}
$$

Onde: 


\begin{tabular}{|c|l|}
\hline A & Primeiro estágio de alteração \\
\hline B & Segundo estágio de alteração \\
\hline C & Terceiro estágio de alteração \\
\hline Na & Número total de alterações de $1^{\circ}$ estágio \\
\hline Nb & Número total de alterações de $2^{\circ}$ estágio \\
\hline Nc & Número total de alterações de $3^{\circ}$ estágio \\
\hline
\end{tabular}

Foram estabelecidas ainda, relações entre os valores de I e os efeitos nos órgãos, descritos na tabela 2 .

Tabela 3 Relação entre os valores que compõem a fórmula que representa o estágio de alterações devido à contaminação dos HPAs, onde relaciona-se I aos efeitos nos órgãos.

\begin{tabular}{ll}
\hline Valores de I & Efeitos \\
\hline $0-10$ & Órgão funcionamento normal \\
$11-20$ & Órgão com alterações de leves a moderadas \\
$21-50$ & Órgão com alterações de moderadas a graves \\
$51-100$ & Órgão com alterações graves \\
$>100$ & Órgão com danos irreversíveis \\
\hline \hline
\end{tabular}

\subsection{Análise Estatística}

Os dados numéricos obtidos foram avaliados por meio da análise de variância ANOVA critério único, seguido pelo teste de Tukey. Foi utilizado o programa estatístico GraphPadInStat. Diferenças foram consideradas significativas quando $\mathrm{p}<0,05$. 


\section{RESULTADOS}

Com a análise microscópica do fígado dos animais do grupo controle, observaram-se vacuolização citoplasmática e hepatócitos com citoplasma homogêneo formando cordões hepáticos (Figura 7).

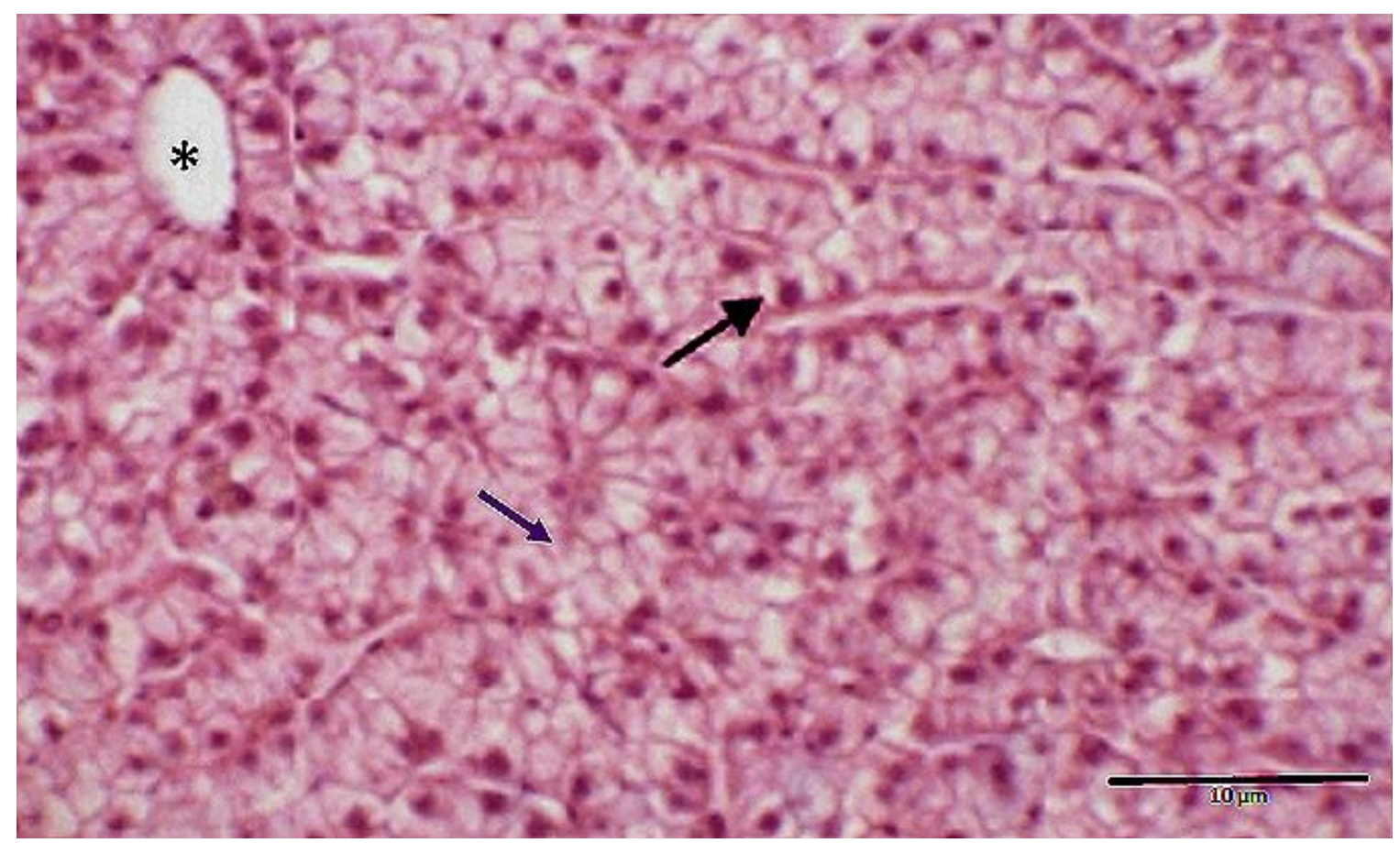

Figura 7: Fotomicrografia do corte histológico do fígado de Rachycentron canadum, grupo controle. O asterisco indica a presença de um vaso sanguíneo, a seta preta indica hepatócitos formando cordões hepáticos e a seta roxa indica vacuolização citoplasmática. Coloração Hematoxilina - Eosina. Escala 10 $\mu \mathrm{m}$.

Foram feitas as análises de densidade de vasos sanguíneos hepáticos, onde resultou em uma média de 8 vasos sanguíneos $( \pm 2)$ para os animais dos grupos controle, uma média de 10 vasos sanguíneos $( \pm 2)$ para os animais expostos aos HPAs por 7 dias e uma média de 11 vasos sanguíneos $( \pm 1)$ para os animais expostos aos HPAs por 14 dias. Não foi observada diferença estatística significativa.

Com a análise morfométrica do núcleo dos hepatócitos, nota-se uma média de $8,34 \mu \mathrm{m}^{2}( \pm 1,95)$ para os animais controles, uma média de $10,75 \mu \mathrm{m}^{2}( \pm 1,93)$ para os animais expostos aos HPAs por 7 dias e uma média de $12,23 \mu \mathrm{m}^{2}( \pm 2,89)$ para os animais expostos aos HPAs por 14 dias, ocasionando uma diferença estatística significativa ( $\mathrm{p}=0,0001)$ entre o grupo controle, o grupo exposto aos HPAs por 7 dias e 
os expostos aos HPAs por 14 dias, caracterizando aumento no volume nuclear (Figura 8).

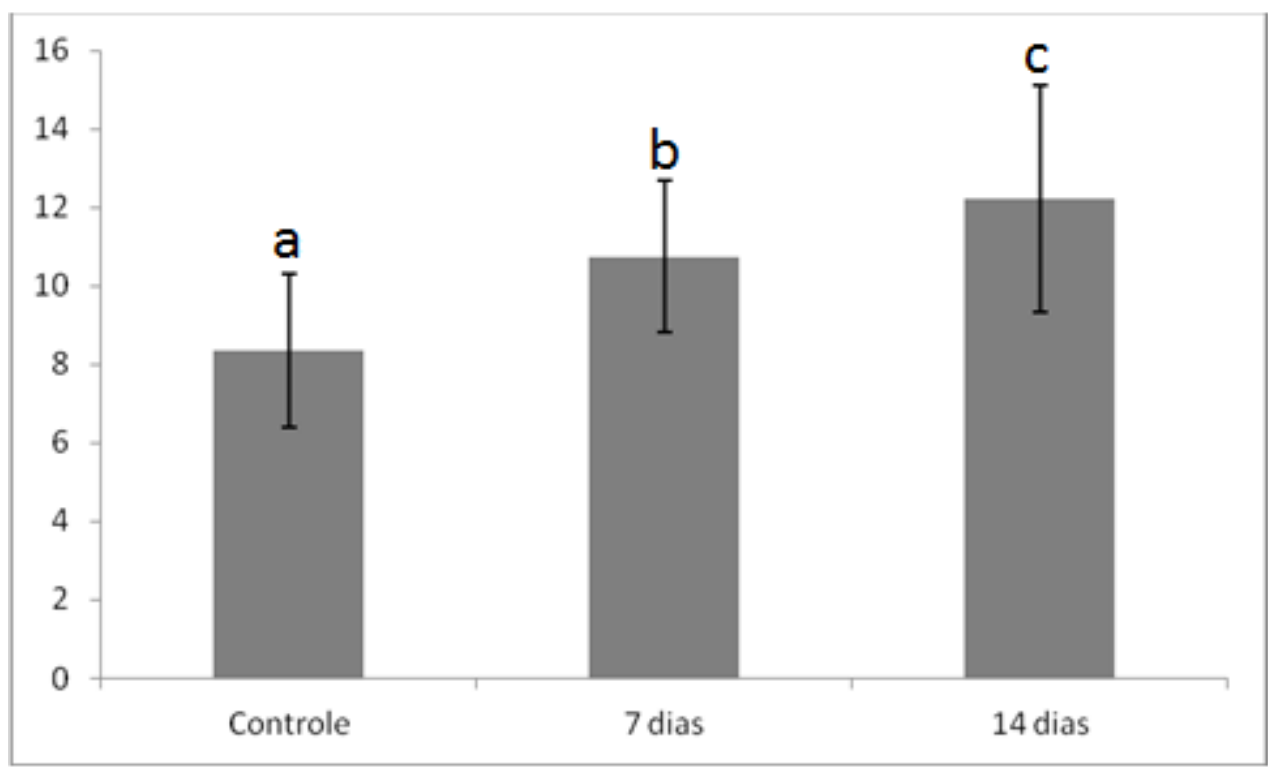

Figura 8. Análise morfométrica da média dos núcleos de hepatócitos de Rachycentron canadum, indicando o grupo controle e os expostos aos HPAS por 7 e 14 dias na concentração de 0,4 ppm. Foi encontrada diferença estatística entre o grupo controle e os grupos expostos aos HPAs. Anova seguido do teste de Tukey $(* \mathrm{p}<0,5)$.

Foram observados nos grupos dos animais expostos em HPAs uma intensa vacuolização citoplasmática, e hiperemia dos vasos hepáticos (Figura 9, figura 10) comparando-se aos animais controle. 


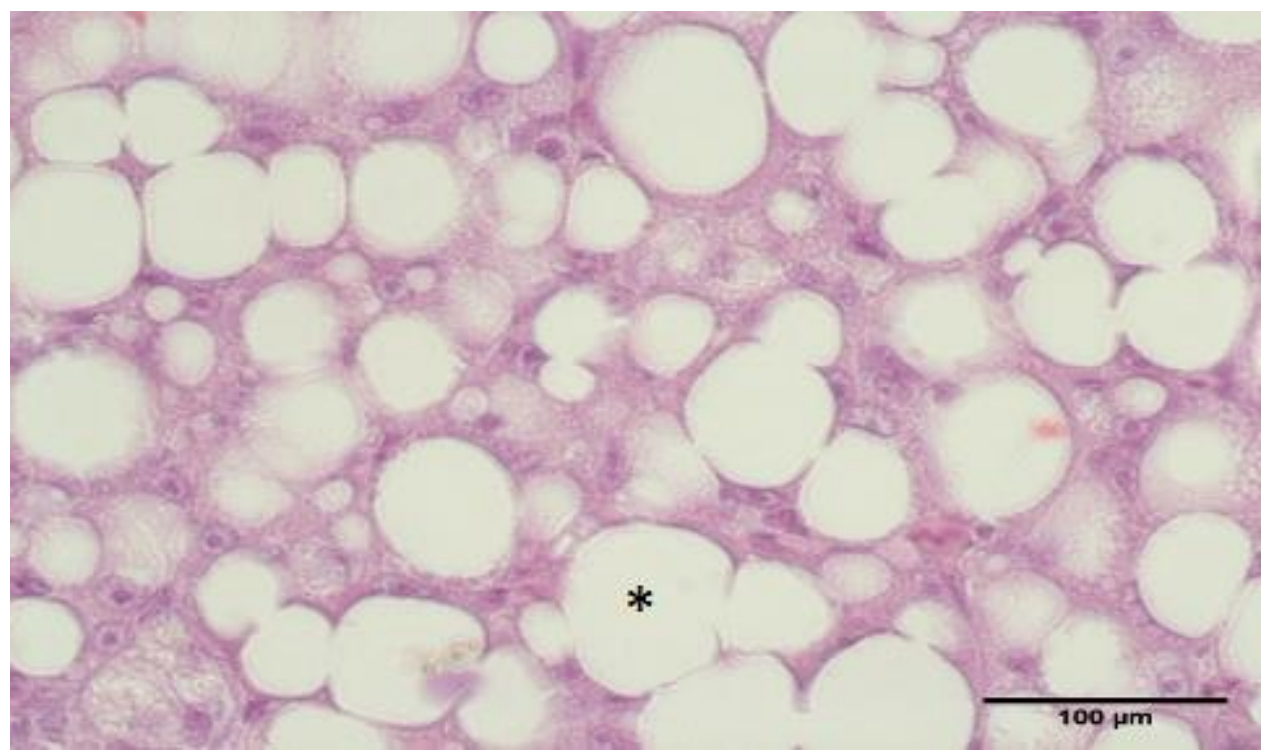

Figura 9. Fotomicrografia do corte histológico do fígado de Rachycentron canadum, grupo exposto à concentração de $0,4 \mathrm{ppm}$ de HPAs por 7 dias. $\mathrm{O}$ asterisco indica intensa vacuolização

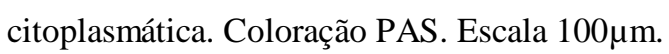

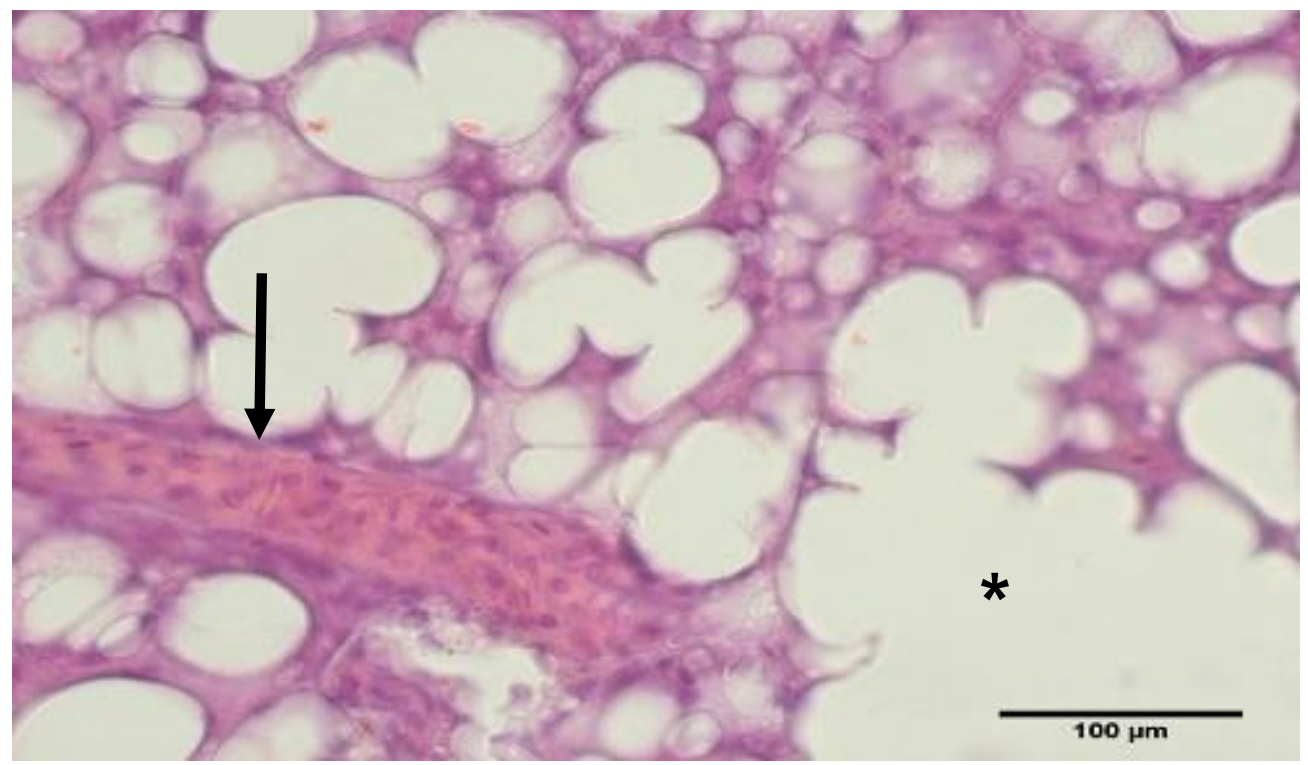

Figura 10. Fotomicrografia do corte histológico do fígado de Rachycentron canadum, grupo exposto à concentração de 0,4ppm de HPAS por 14 dias. O asterisco indica intensa vacuolização citoplasmática; a seta preta indica hiperemia dos vasos hepáticos. Coloração PAS. Escala $100 \mu \mathrm{m}$.

Com a aplicação do Índice de Alteração Histológica do fígado obteve-se I=0 para os animais controle, caracterizando como órgão funcionalmente normal, I=22 para os animais expostos aos HPAs por 7 dias, caracterizando em órgão com alterações moderadas a grave e $\mathrm{I}=23$ para os animais expostos aos HPAs por 14 dias, caracterizando em órgão com alterações moderadas a grave (Figura 11). 


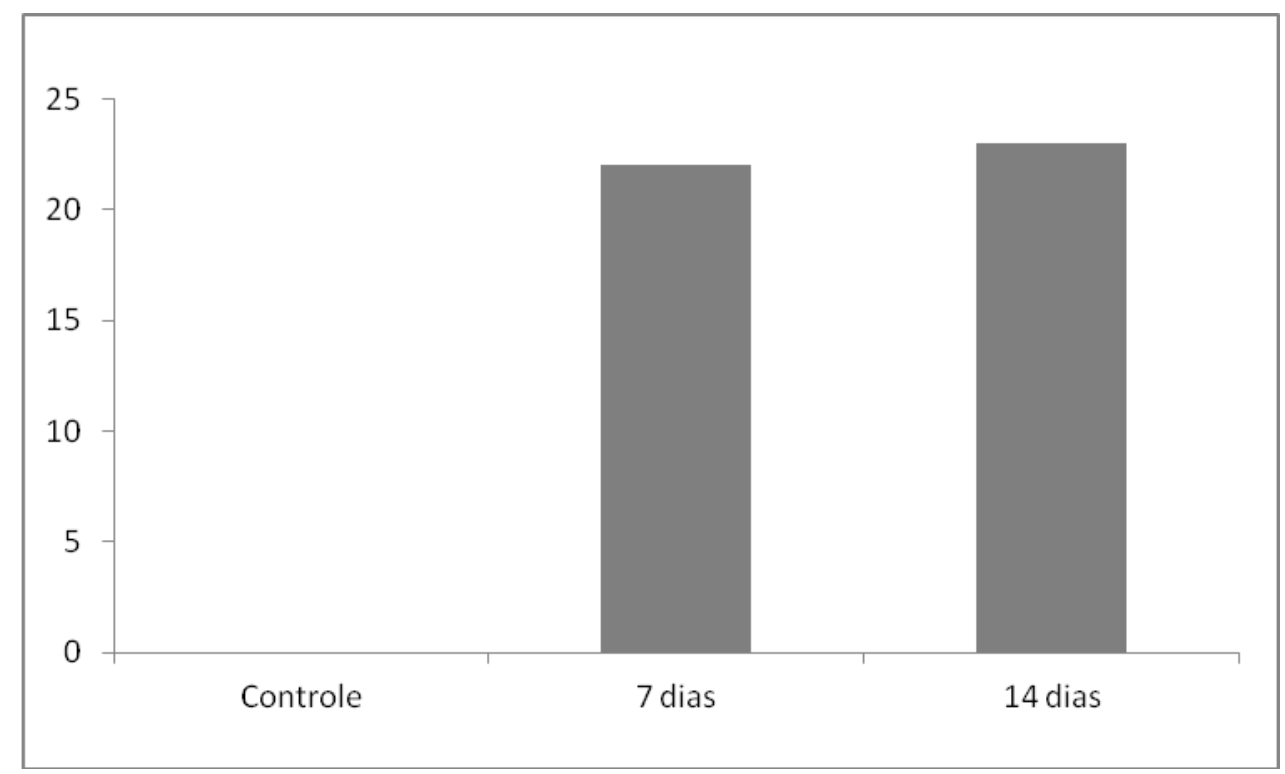

Figura 11. Análise do Índice de Alteração Histológica (I.A.H.) do fígado de Rachycentron canadum, indicando alterações histológicas do grupo controle e dos grupos expostos aos HPAs por 7 e 14 dias na concentração de $0,4 \mathrm{ppm}$. O grupo controle foi classificado com I=0 caracterizando o fígado como normal, o grupo exposto por 7 dias foi classificado com $\mathrm{I}=22$ e o grupo exposto por 14 dias classificado com I=23, caracterizando o fígado de ambos os grupos com alterações moderadas a graves.

Com o cálculo do índice hepatossomático (I.H.S.), observou-se uma média de $3,47( \pm 0,40)$ para os animais do grupo controle; média de 7,08 $( \pm 0,81)$ para os animais do grupo exposto aos HPAs por 7 dias e média de 5,69 $( \pm 2,28)$ para os animais do grupo exposto aos HPAs por 14 dias respectivamente. Foi observada diferença estatística significativa no IHS entre o grupo controle e os grupos expostos aos HPAs 7 dias ( $\mathrm{p}=0,033)$ e HPAs 14 dias ( $\mathrm{p}=0,045)$ (Figura 12). 


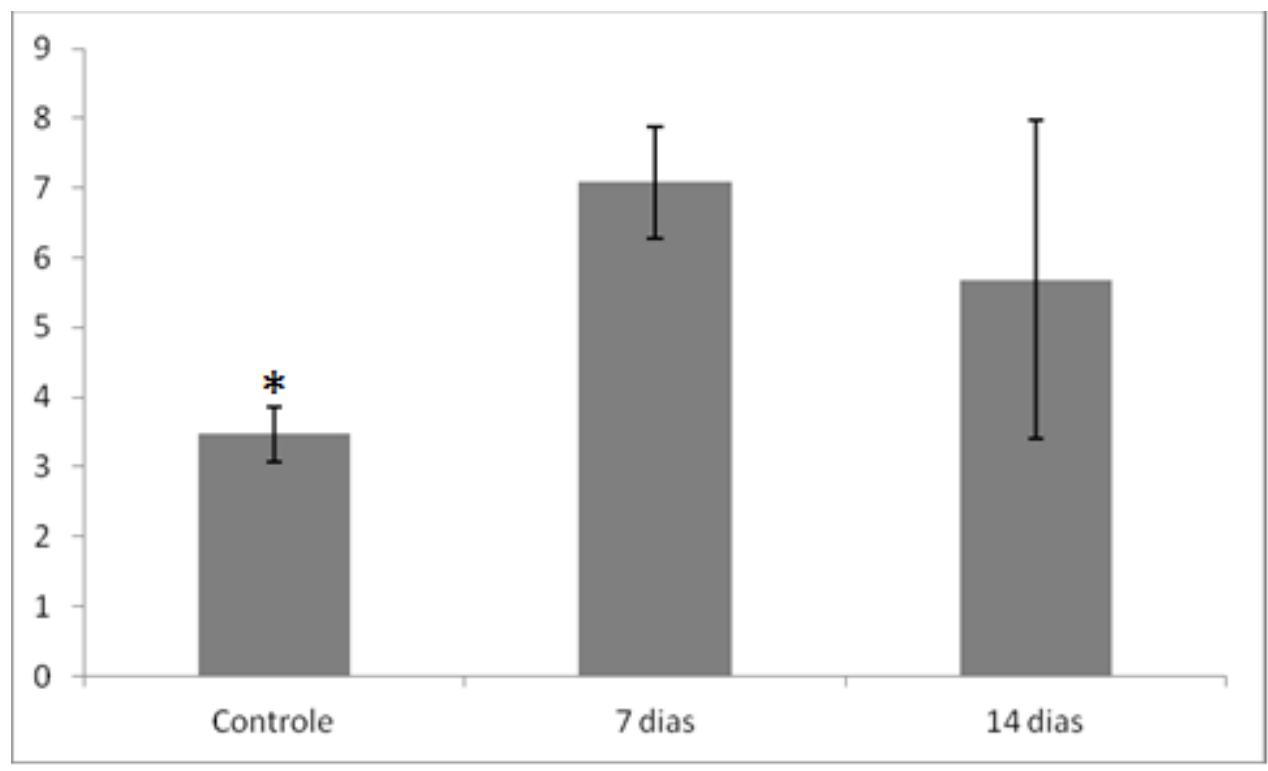

Figura 12. Análise do Índice Hepatossomático (I.H.S.) de Rachycentron canadum, indicando os grupos controle e os expostos aos HPAs por 7 e 14 dias na concentração de 0,4ppm. Foi encontrada diferença estatística significativa entre os grupos controle e os expostos aos HPAs. Anova seguido do teste de Tukey $(* \mathrm{p}<5)$.

Com a análise de parâmetros metabólicos para confirmar a eficiência do fígado, foi mensurada a proteína total, onde foi obtida média de $2,17( \pm 0,45)$ para os animais do grupo controle, média 3,02 $( \pm 0,38)$ para os animais expostos por 7 dias e média 2,82 $( \pm 0,34)$ para os animais expostos por 14 dias. Não houve diferença estatística (figura $13)$.

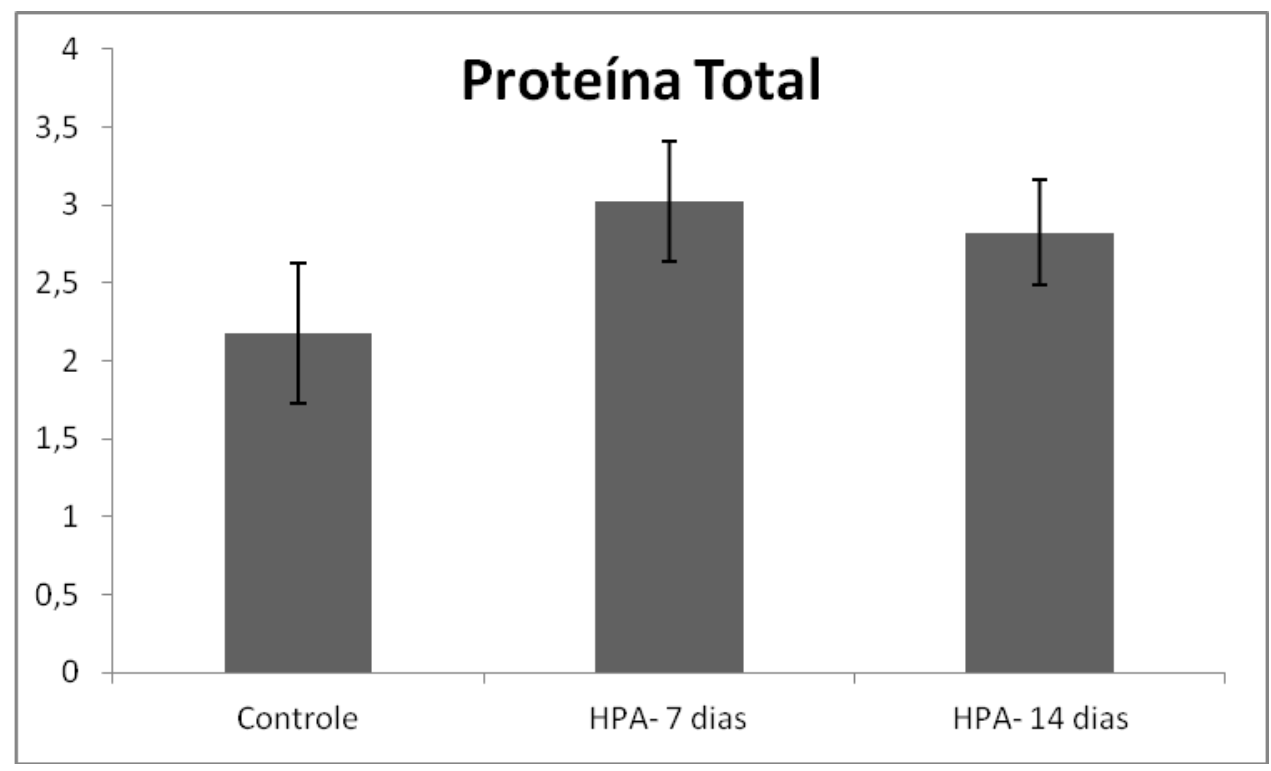

Figura 13. Quantificação da proteína total plasmática de Rachycentron canadum, dos grupos controle e os grupos expostos aos HPAs por 7 e 14 dias na concentração de 0,4ppm. Não houve diferença estatística. Anova seguido do teste de Tukey $(* \mathrm{p}<5)$. 
Para análise dos parâmetros metabólicos para estressores, foi mensurado o cortisol como indicador primário de estresse, onde foi observado uma média de 24,01 $\mathrm{mg} / \mathrm{dL}( \pm 1,67)$ para os animais do grupo controle, média de $17,54 \mathrm{mg} / \mathrm{dL}( \pm 3,63)$ para os animais expostos por 7 dias, e média $22,12 \mathrm{mg} / \mathrm{dL}( \pm 2,79)$ para os animais expostos por 14 dias. Não houve diferença estatística significativa (figura 14).

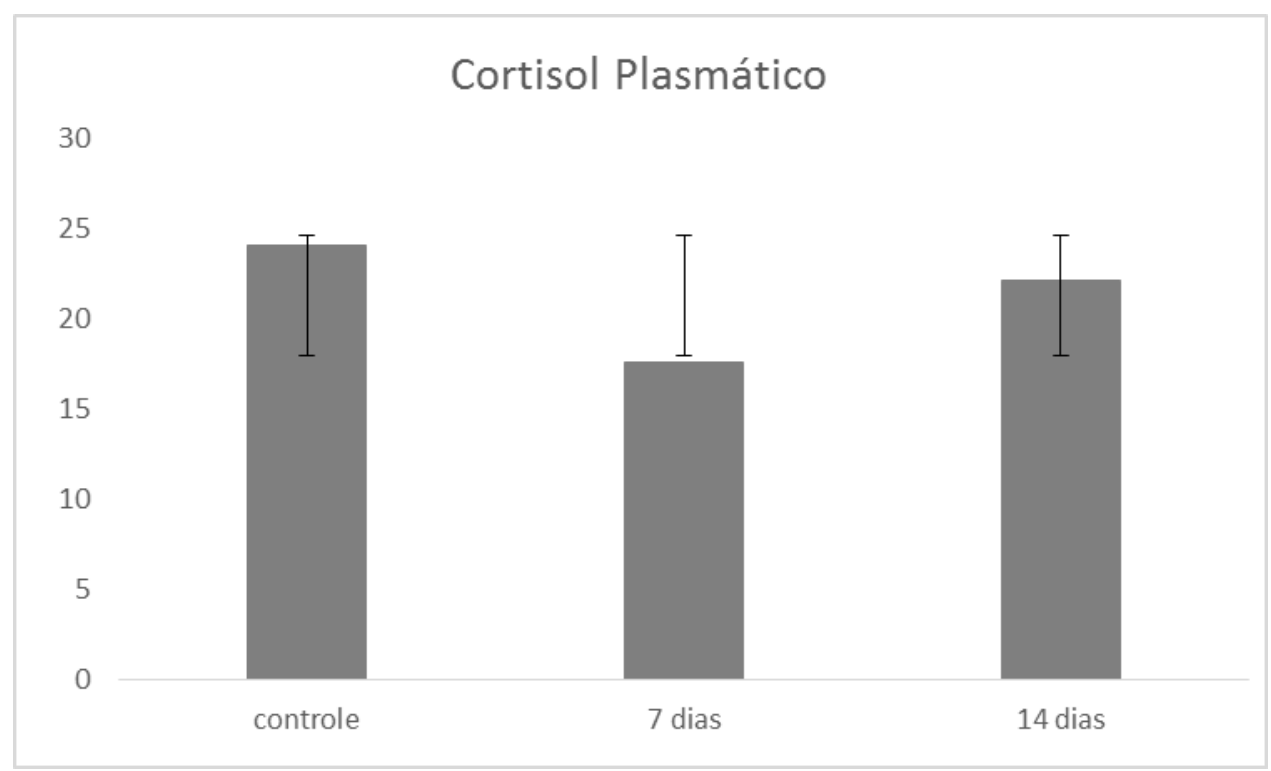

Figura 14. Quantificação dos níveis de cortisol plasmático de Rachycentron canadum, nos grupos controle e os grupos expostos aos HPAs por 7 e 14 dias na concentração de 0,4ppm. Não houve diferença estatística significativa. Anova seguido do teste de Tukey, $\left({ }^{*} \mathrm{p}<5\right)$.

Foi analisada a glicose como parâmetro secundário, sendo observada média de $19,34 \mathrm{mg} / \mathrm{dL}( \pm 5,06)$ para os animais do grupo controle, média de $27,11 \mathrm{mg} / \mathrm{dL}( \pm 8,98)$ para os animais expostos por 7 dias e média $23,92 \mathrm{mg} / \mathrm{dL}( \pm 3,71)$ para os animais expostos por 14 dias. Não houve diferença estatística significativa (figura 15). 


\section{Glicose Plasmática}

24

23

22

21

20

19

18

Figura 15. Quantificação dos níveis de glicose plasmática Descrição de Rachycentron canadum, nos grupos controle e os grupos 7 e 14 dias na concentração de 0,4ppm. Não houve diferença estatística significativa entre os grupos. Anova seguido do teste de Tukey $(* \mathrm{p}<5)$.

Foi feita análise dos níveis de lactato para indicar parâmetros secundários de estresse, sendo obtida uma média de $2,24 \mathrm{mg} / \mathrm{dL}( \pm 0,49)$ para os animais do grupo controle, média $2,82 \mathrm{mg} / \mathrm{dL}( \pm 0,35)$ para os animais expostos por 7 dias e média 2,12 $\mathrm{mg} / \mathrm{dL}( \pm 0,22)$ para os animais expostos por 14 dias. Não houve diferença estatística significativa (figura 16).

\section{Lactato Plasmático}

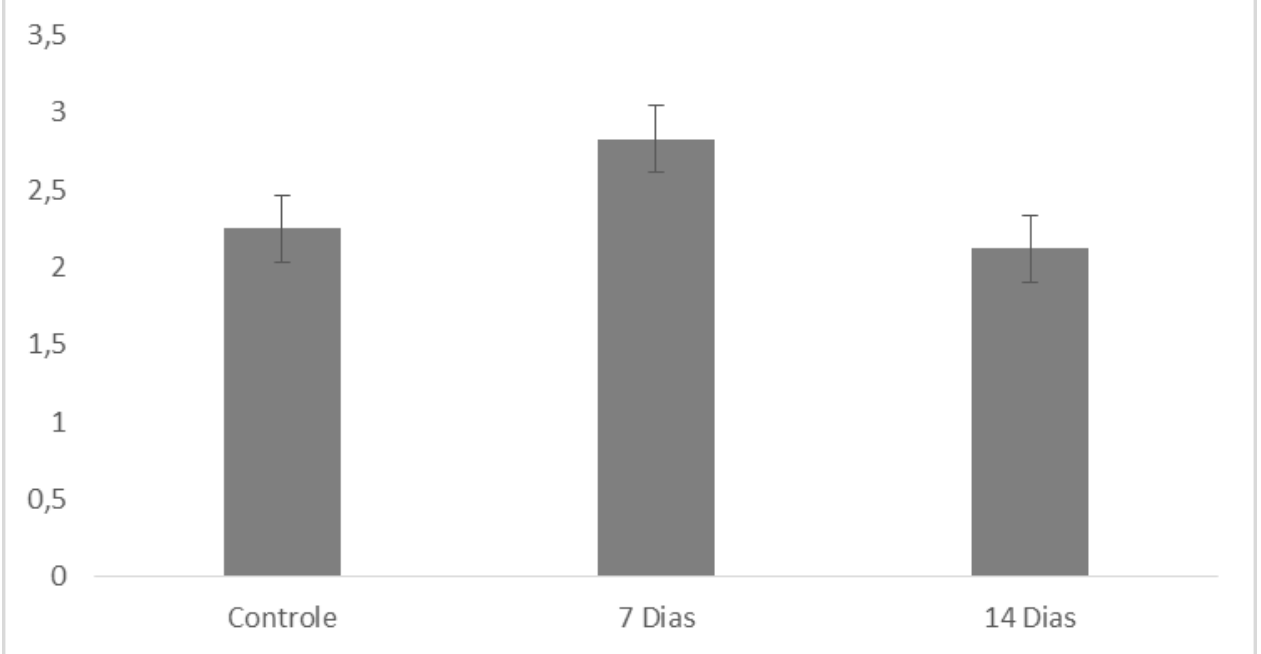

Figura 16. Quantificação dos níveis de lactato plasmático de Rachycentron canadum), nos grupos controle e os grupos expostos aos HPAs por 7 e 14 dias na concentração de $0,4 \mathrm{ppm}$. Não houve diferença estatística. Anova seguido do teste de Tukey $\left({ }^{*} \mathrm{p}<5\right)$. 


\section{DISCUSSÃO}

Atualmente, com a descoberta da camada do pré-sal em território nacional, o Brasil torna-se um dos principais países com potenciais para produção e exportação de petróleo e seus derivados. Mas apesar desta descoberta poder impulsionar a economia do país, ao mesmo tempo traz a preocupação de que como isso pode afetar o meio ambiente, pois com o aumento da demanda por petróleo, aumentam também os riscos ambientais e de saúde pública, uma vez que este combustível possui alto risco de contaminação, que engloba todas as esferas ambientais.

Existe um esforço mundial para o desenvolvimento de novas fontes energéticas renováveis e não renováveis, popularmente conhecidas como "energia limpa". Apesar desses esforços, a dependência dos combustíveis fósseis ainda é muito grande. Além disso, seus derivados como polímeros plásticos, óleos lubrificantes, asfalto, ceras, medicamentos, dentre outros, estão fortemente inseridos em nossa cultura, e isso acontece devido ao grande crescimento populacional.

Um dos impactos que esse xenobiótico pode acarretar é a diminuição de várias espécies de peixes, pois estes animais têm necessidade de total interação com o ambiente em que vivem, e como consequência desta característica pode haver o comprometimento em seu desempenho reprodutivo, mudanças de comportamento e suscetibilidade a doenças. Índices apontam que está ocorrendo uma diminuição em nível mundial nos estoques de peixes nos oceanos, causados pela pesca predatória, por alterações de fatores abióticos múltiplos, dentre eles a contaminação das águas. Além disso, os fatores de estresse têm sido a principal causa das perdas de lucro na piscicultura, pois afeta o metabolismo, o crescimento dos peixes e consequentemente sua reprodução (BARTON, et al., 1991; LIMA, et al., 2006).

Para demonstrarmos os efeitos que este xenobiótico pode causar, foram realizados bioensaios para avaliar qual o grau de impacto da contaminação por HPAs em organismos utilizados como bioindicadores.

A mensuração dos biomarcadores de estresse mostraram que os animais não sofreram alterações suficientes para chegar ao nível de ser irreversível ou causar danos permanentes.

De acordo com Brandão (2006), o cortisol ativa respostas do corpo mediante situações de emergência ou quando o animal se depara com novas condições no meio em que vive, como por exemplo, a presença de xenobióticos. O sistema imune ativa a 
liberação do cortisol para auxiliar o animal a superar as novas condições, ou mesmo se adequar a elas. Nem sempre esta situação é considerada ideal, conduzindo o animal a um estado de estresse (WANDELAAR BONGA, 1997).

Neste estudo, considerando os resultados obtidos, os grupos que ficaram expostos ao xenobiótico demonstraram certa adequação à situação de estresse.

Para avaliar o parâmetro secundário de estresse, foram analisados os níveis de glicose plasmática nos peixes dos grupos controle e dos animais expostos ao xenobiótico. De acordo com Silveira (2009) e Tiihonem (1995), quando os peixes se deparam com situações de estresse, a concentração de glicose no plasma sanguíneo é aumentada, e esta glicose tem como origem o glicogênio que é oriundo do fígado. $\mathrm{E}$ como resultado, o animal terá uma energia adicional para suprir a demanda exigida para outros tecidos além do fígado e conseguir superar a situação de estresse em que esteja envolvido (ALURU; VIJAYAN, 2007). No presente trabalho, os níveis de glicose plasmática não apresentaram diferenças significativas entre os grupos avaliados. Porém, observaram-se respostas tendenciosas para os grupos expostos aos HPAs, como mostrado na figura 16.

Outro parâmetro secundário de estresse avaliado em nosso trabalho foi à medida de níveis de lactato plasmático. O lactato é produzido após a queima da glicose, sendo o produto final dessa degradação, o qual fornece uma fonte alternativa de energia sem a utilização de oxigênio.

Tratando-se de peixes, segundo Randall; Perry (1992), o lactato pode ter seus níveis aumentados no caso de estresse agudo, como por exemplo, no manejo dos animais, na captura ou em situação de hipóxia.

Em grande concentração no organismo, o lactato pode produzir hiperacidez, o que pode ser decorrente de um estado de estresse (NELSON; COX, 2011; SILVEIRA, et al., 2009). Com os dados obtidos no presente estudo, os níveis de lactato plasmáticos não apresentaram diferenças significativas entre os grupos avaliados.

Para a resposta terciaria, foi realizada a avaliação histológica do fígado. Este órgão pode metabolizar e/ou bioacumular xenobióticos, sendo assim, utilizamos o índice hepatossomático (IHS), que possibilita a quantificação do estoque energético do animal (ROSETY-RODRIGUEZ, et al., 2002; TAKASIMA; HIBIYA, 1995).

Não foi observada diferença estatística significativa entre o grupo controle e os grupos expostos ao xenobiótico. 
As variações mais comuns que refletem no IHS podem ser decorrentes de alterações dos hormônios sexuais e da alimentação (COSTA, et al., 2005). Neste bioensaio, os peixes eram filhotes, portanto não estavam sexualmente maduros, e todos foram alimentados da mesma forma, seguindo a indicação obtida na literatura (COSTA, et al., 2005). Também foi utilizado o fator de condição (FC), que indica o estado geral do peixe, estimando seu estado de saúde. De acordo com Figueiredo-Fernandes (2006), o aumento no fator de condição pode ser um indicativo de efeitos tóxicos. Outros estudos mostram que uma diminuição no fator de condição, assim como no IHS, pode ocorrer em peixes que foram contaminados por xenobióticos (SALVO, et al., 2012). Por outro lado, muitos estudos demonstraram que peixes expostos a poluentes ambientais não apresentam diferenças estatísticas significativas entre os grupos controle e expostos aos xenobióticos (OOST, et al., 1998), sendo este o resultado que obtivemos neste estudo. Os animais que foram expostos aos HPAs tanto por 7 dias quanto 14 dias, não apresentaram diferenças estatísticas significativas quando comparados aos grupos controle.

Nos animais expostos aos HPAs, foi identificada intensa vacuolização citoplasmática nos hepatócitos, o que pode ser um indicativo de processos degenerativos decorrentes de problemas metabólicos, possivelmente devido à exposição aos HPAs (TAKASHIMA; HIBIYA, 1995). Outra alteração encontrada foi desarranjo dos cordões hepáticos, que pode ter sido causada pela intensa vacuolização apresentada por estas células.

Foi encontrado também hiperemia dos vasos hepáticos nos animais expostos aos HPAs. A hiperemia pode ser colocada como uma adaptação, onde ocorre o aumento de células sanguíneas, provavelmente por um aumento do fluxo sanguíneo no tecido hepático, facilitando assim, o transporte de nutrientes e melhorando a oxigenação em áreas com possíveis injúrias. Pelas análises de densidade dos vasos sanguíneos hepáticos não obtivemos diferenças estatísticas significativas entre os grupos estudados. Já na análise morfométrica do núcleo dos hepatócitos, observamos uma diferença estatística significativa, com o aumento no volume nuclear dos animais experimentais quando comparados ao grupo controle, o que pode ser resultado de um aumento da atividade metabólica nos hepatócitos (TAKASHIMA; HIBIYA, 1995).

Para análise complementar terciária, foram quantificadas as proteínas totais, que são compostas basicamente por albumina e globulinas, essenciais para células e tecidos. 
Segundo Ranzani Paiva; Silva-Souza (2004), com a determinação das proteínas totais pode-se determinar se existe alguma anormalidade ocorrendo com o indivíduo. Os resultados obtidos neste ensaio não apresentaram diferenças estatísticas significativas no que se refere à quantificação das proteínas totais, sugerindo que os animais se mantiveram nas mesmas condições de saúde antes e após os tratamentos.

No presente estudo foram encontradas alterações no fígado dos peixes expostos aos HPAs. Estas alterações histológicas identificadas nos animais experimentais são semelhantes às encontradas por diversos autores. Akaish (2004), encontrou alterações semelhantes nos peixes Astyanax sp, ao estudar os efeitos da exposição aguda por FSA, e com esses dados, conseguiu-se ressaltar a importância e a relevância de estudos que determinem alterações histológicas em órgãos suscetíveis a contaminação por HPAs. Com isso será mais fácil prever os possíveis impactos nas populações de peixes com potencial bioindicador, e buscar respostas e soluções para as populações de animais atingidas por esse xenobiótico.

Os dados obtidos no presente trabalho podem representar, de acordo com Lima (2006) e Aluru; Vijayan (2007), uma adaptação que estes animais sofreram, o que representa a conservação de algumas funções fisiológicas e alterações de outras, indicando que estes estudos devem ser aprofundados. 


\section{CONCLUSÃO}

Conclui-se que os HPAs em uma concentração de 0,4 ppm ocasionaram uma serie de modificações no fígado, levando o animal a alterações histológicas deste órgão.

Os resultados obtidos dos parâmetros estressores avaliados não foram alterados considerando os animais experimentais e controle, oque pode indicar uma adequação dos animais aos fatores estressantes, no caso, os HPAs.

A espécie Rachycentron canadum foi um excelente bioindicador, por suas características comportamentais e respostas aos parâmetros analisados, mostrando resposta eficaz em todos os bioensaios.

$\mathrm{O}$ presente estudo acresce mais uma ferramenta para intensificar o biomonitoramento de áreas que possam estar impactadas pelo HPAs. 


\section{REFERÊNCIAS*}

AAS, E.; BEYER, J.; GOKSOIR, A. Fixed wavelength flourescence (FF) of bile as a monitoring tool for polyaromatic hydrocarbon exposure in fish: an evoluation of compound specificity, inner filter effect and signal interpretation. Biomarkers, v.5, p. 9-23, 2001.

ABADIE, E. Processos de Refinação. Rio de Janeiro: Petrobrás, 1999. 150 p.

ADAMS, S. M.; MCLEAN, R. B. Estimation of larger mouth bass, Micropterussalmoides Lacèpéde growth using the liver somatic index and physiological variables. Journal of Fish Biology, v. 26, p. 111 -126, 1985.

AKAISHI, F. M. Morphological and Neurotoxicological Findings in Tropical Freshwater Fish (Astyanax sp.) After Waterborne and Acute Exposure to Water Soluble Fraction (WSF) of Crude Oil. Archives of Environmental Contamination and Toxicology, v. 46, p. 244-253, 2004.

ALCARAZ, G.; ESPINA, S. Acute toxicity of nitrite in juvenile grass carp modified by weight and temperature. Bulletin, Environmental Contamination and Toxicology, v.55, p. 473-478, 1995.

ALURU, N.; VIJAYAN, M. M. Hepatic transcriptomic response to glucocorticoid receptor activation in rainbow trout. Physiology Genomics, v.31, p. 483-491, 2007.

ALURU, N.; VIJAYAN, M. M. Stress transcriptomics in fish: A role for genomic cortisol signaling. General and Comparative Endocrinology, v. 164, p. 142-150, 2009.

ARENDT, M. D.; OLNEY, J. E.; LUCY, J. A. Stomach content analysis of cobia, Rachycentron canadum, from lower Chesapeake Bay. Fish Bulletin, v. 99, p. 665-670, 2001

BAGENAL, T. B.; TESCH, F. W., Methods for assessment of fish production in fresh waters, 3rd edition. Oxford: Blackwell Scientific Publications, England, 1978. $365 \mathrm{p}$. 
BARROS, M. M. Nutrição e saúde de peixes. In: Congresso Latino Americano de Nutrição Animal. [Anais] Piracicaba: CBNA - AMENA, 2006. p.1-15.

BARTON, B. A.; IWAMA, G. K. Physiological changes in fish from stress in aquaculture with emphasis on the response and effects of corticosteroids. Review of Fish Diseases, p. 3-26, 1991.

BARTON, B. A.; MORGAN, J. D.; VIAJAYAN, M. M. Physiological and condition related indicators of environmental in fish in: Adams biological indicator of aquatic ecosystem stress, American Fisheries Society, p. 289-320, 2002.

BEG, M. U.; GEVAO, B.; AL_JANDAL, N.; BEG, K. R.; BUTT, S. A.; ALI, N.; ALHUSSAINI, M. Polycyclic aromatic hydrocarbons in three varieties of fish from Kuwait bay. Polycyclic Aromatic Compounds, v. 29, n 2, p. 75-89, 2009.

BENNETI, D. D.; MEHMET, R. O.; SARDENBERG, B. B.; WELCH, A.; HOENIG, R.; ZINK, I.; RIVERA, J. A.; DONALD BACOAT, B. D.; PALMER, K.; CAVALLIN, F. Advances in hatchery and grow-out technology of cobia Rachycentron canadum (Linnaeus). Journal of Fish Diseases, v. 39, p. 701-711, 2008.

BERNET, D.; SCHIMIDT, H.; MEIER, W.; BURKHARDT-HOLM, P.; WAHLI, T. Histophatology in fish; proposal for a protocol to assess aquatic pollution. Journal of Fishes Diseases, v. 22, p. 25-34, 1999.

BRANDÃO, F. R.; GOMES, L. C.; CHAGAS, E. C. Respostas de estresse em pirarucu (Arapaimas gigas) durante práticas de rotina em psicicultura. ACTA AMAZONICA, v. 36, p. 349-356, 2006.

CANTAGAllo, C.; CARlOS, C. J.; DIAS-BRITO D. Limpeza de ambientes costeiros brasileiros contaminados por petróleo: uma revisão, Pan-American Journal of A. S., v. 2, p. 1-12, 2007.

CARLSON, R. E.; ANDERSON, D. P.; BODAMMER, J. E. In vivo cortisol administration suppreses the in vitro primary immune response of winter flounder lymphocytes. Fish Shell fish Immunology, v. 3, p. 299-312, 1993.

CARRIÓN, R. L.; DEL RIO, M, P, M.; MIGUEZ, J. M.; MANCERA, J. M.; SOENGAS, J. L. Influence of cortisol on osmorregulatin and energy metabolism in 
gilthead seabream sparus aurata, Journal of Experimental Zoology, v. 298, p. 105$118,2003$.

CAVALLI, R. O \& HAMILTON, S. Piscicultura marinha no Brasil com ênfase na produção do beijupirá, Marine fish farming in Brazil with emphasis on cobia production, Revista Brasileira de Reprodução Animal, v. 6, p. 64-69, 2009.

COSTA, A. P. R.; ANDRADE, D. R.; VIDAL, M. V.; SOUZA, G. Indicadores quantitativos da biologia reprodutiva de fêmeas de piau vermelho no Rio Paraíba do Sul. Pesquisa Agropececuaria Brasileira, Brasília, v. 40, n. 8, p. 789-795, 2005.

FAULK, C. K.; KAISER, J. B.; HOLT, J. Growth and survival of larval and juvenile cobia Rachycentron canadum in a recirculating raceway system, , Aquaculture, v. 270, p. 149-157, 2007.

FERREIRA, M. S., OLIVEIRA, A. M., VALE, A. L. Velocidade crítica de natação (Ucrit) de matrinxã (Bryconamazonicus) após exposição à hipoxia, Instituto Nacional de Pesquisas da Amazônia, v. 40, p. 699-704, 2010.

FIGUEIREDO-FERNANDES, A.; FERREIRA-CARDOSO, J. V.; GARCIA-SANTOS, S.; MONTEIRO, S. M.; CARROLA, J.; MATOS, P.; FONTAINHAS-FERNANDES, A. Histopathological changes in liver and gill epithelium of Nile tilapia, Oreochromisniloticus, exposedtowaterborne copper1. Pesquisa Veterinária Brasileira, v. 27, p. 103-109, 2007.

FINNVEDEN, G.; NILSSON, M.; JOHASSON, J.; PERSSON, A. F.; CARLSSON, T. Strategic assessment methodologies - applications within the energy sector, environmental impact assessment. Elsevier Science, p. 1-33, 2002.

HAMILTON, M. A., RUSSO, R. C., THURSTON, R.V., Trimmed spearman-karber method for estimating median lethal concentrations in toxicity bioassays. Environmental Science Technology, v.11, p.714-719, 1977.

HINTON, D. E.; BAUMANN, P. C.; GARDNER, G. R.; HAWKINS, W. E.; HENDRICKS, J. D.; MURCHELANO, R. A.; OKIHIRO, M. S. Histopathologic Biomarkers. In: HUGGETT, R. J.; KIMERLI, R. A.; MEHRLE, P. M.; BERGMAN, H. L. Biomarkers biochemical, physiological and histological markers of anthropogenic stress. Boca Raton: Lewis Pubishers, 1992. cap. 4, p. 155 -196. 
KANEKO, J. J.; HARVEY, J. W.; BRUSS, M. L. Clinical biochemistry of domestic animals. San Diego: Academic Press, 1997. 932 p.

KASSINIS, G. I. A model for estimating pollution emissions for individual economic activities, Elsevier Science, p. 417-438, 1998.

KENNISH, M. Practical Hadbook of Estuarine and Marine Pollution. Boca Raton: Petralia Publications, 1997. 523 p.

KÖCK G, TRIENDL M, HOFER R. Seasonal patterns of metal accumulation in Arctic char (Salvelinus alpinus) from an oligotrophic Alpine lake related to temperature. Journal of Fisheries Aquatic Science, v. 53, p. 780-786, 1996.

LEE, RF; ANDERSON, J.W. Significance of cytochrome P450 system responses and levels of bile fluorescent aromatic compounds in marine wildlife following oil spills. Marine Pollution Bulletin, v.50, p. 705-723, 2005.

LEITE, J. I. A.; VIEIRA, E. C.; FIGUEIREDO, E. A. Química fisiológica. São Paulo: Atheneu, 1995. [300 p.]

LEONARDO, J. M. L. O. Histologia das brânquias de larva da tilápia do Nilo, Oreochromis niloticus (L.), de origem tailandesa, submetidas a diferentes níveis de vitamina C. Acta Scientiarum, v. 23, n. 4, p. 863-870, 2001.

LICHTENFELS, A. J. E. C. et al. Effects of water pollution on the gill apparatus of fish. Journal Comparative Pathology, v. 115, p. 47-60, 1996.

LIMA, L. C.; RIBEIRO, L. P.; MALISON, J. A.; BARRY, T. P.; HELD, J. A. Effects of temperature on performance characteristics and the cortisol stress response of surubim Pseudoplatystoma sp. Journal of the World Aquaculture Society, v. 37, p. 89-95, 2006.

MACLEOD J. C.; PESSAH, E. Temperature effects on mercury accumulation, toxicity, and metabolic rate in rainbow trout (Salmogairdneri). Journal of Fisheries Research Board of Canada, v. 30, p. 485-492, 1973.

MALLAT, J. Fish gill structural changes induced by toxicants and other irritants: a statistical review. Canadian Journal Fisheries Aquatic Science, v. 42, p. 630, 1985. 
MARTINS DA ROCHA, R.; CARVALHO, E. G.; URBINATI, E. C. Physiological responses associated with capture and crowding stress in matrinxa Bryconcephalus (Gunther, 1869). Aquaculture Research, v. 35, p .245-249, 2004.

MILLIGAM, C. L.; WOOD, C. M. Intracellular and extracellular acid-base status and H exchange with the environment after exhaustive exercise in the rainbow trout. Journal of Experiment Biology, v. 123, p. 92-121, 1982.

MOMMSEN, T. P.; VIJAYAN, M. M.; MOON, T. W. Cortisol in teleosts: dynamics, mechanisms of action and metabolic regulation. Reviews in Fish Biology Fisheries, v. 9, p. 211-268, 1999.

NELSON, D. L.; COX, M, M. Princípios de bioquímica. Porto Alegre: Artmed, 2011. $1304 \mathrm{p}$.

NISHIGIMA, F. N.; WEBER, R. R.; BÍCEGO M. C. Aliphatic and aromatic hydrocarbons in sediments of Santos and Cananéia, SP, Brazil, Norwegian waters, Marine Policy, v. 31, p. 19-31, 2001.

OLIVEIRA RIBEIRO, C. A.; PELLETIER, É.; PFEIFFER, W. C. E ROULEAU, C. Comparative uptake, bioaccumulation, and gill damages of inorganic mercury in tropical and nordic freshwater fish. Environmental Research Section A, v. 83, p. 286$292,2000$.

OOST, R. V. D.; BEYER, J., VERMEULEN, N. P. E. Fish bioaccumulation and biomarkers in environmental risk assessment: a review. Environmental Toxicology and Pharmacology, v. 13, p. 57-149, 2003.

ORNELlAS, M. R.; AZEREDO, A.; TORRES, J. P. M. Aspectos ecotoxicológicos de hidrocarbonetos policíclicos aromáticos, Oecologia Brasiliensis, v. 2, p. 188-201, 2007.

PRASAD, M. S. SEM study on the effects of crude oil on the gills and airbreathing organs of climbing perch Anabas testudineus. Bulletin of Environmental Contamination and Toxicology, v.47, p. 882-889, 1991.

PEREIRA, C. A.; MARTINEZ, C. B. R. Alterações histológicas em brânquias e rim de Curimbas após exposição aguda à gasolina. In: Anais do XVI EAIC, Santos, 2007. 
POLEKSIC, V.; MITROVIC-TUTUNDŽIC, V. Fish gills as a monitor of sublethal and chronic effects of pollution. In: MÜLLER, R.; LLOYD, R. (eds.) Sublethal and chronic effects of pollutants on freshwater fish. Oxford: Fishing News Books, 1994. cap. 30, p. 339-352.

RANDAll, D. J.; PERRY, S. F. Catecholamines. Fish Physiology, v. 12, p. 255-300, 1992.

RANZANI - PAIVA, M. J.; SILVA - SOUZA, A. T. Hematologia de peixes brasileiros. São Paulo: Varela, 2004. [120 p.]

ROSETY-RODRÍGUEZ, M.; ORDONEZ, F. J.; ROSETY, J. M.; ROSETY, I.; RIBELLES, A.; CARRASCO, C. Morpho - histochemical changes in the gills of turbot, Scophthalmusmaximus L., induced by sodium dodecyl sulfate. Ecotoxicology and Environmental Safety, v. 51, p. 223 - 228, 2002.

SALVO, LM; MALUCELLI, BE; BACILA, M.; SANCHEZ, D.O.; NICARETTA, L.C. KLEMZ, C.; SILVA DE ASSIS, H.C. Effects of endosulfan sublethal concentrations: on carp (Cyprinuscarpio, Linnaeus, 1758): morphometric hystologic, ultrastructural analyses and cholinesterase activity evaluation. Brazilian Journal of Veterinary Research and Animal Science, v. 45, p. 87-94, 2008.

SALVO, L. M.; BAINY, A. C.; VENTURA, E. C.; MARQUES M. R.; SILVA, J. R.; KLEMZ C.; SILVA DE ASSIS, H. C. Assessment of the sublethal toxicity of organochlorine pesticide endosulfan in juvenile common carp (Cyprinus carpio). Journal of Environmental Science Health A Toxic Hazardous Substances Environmental Engineering. v. 47, p. 1652-1658, 2012.

SAlVO, L. M.; SILVA, J. R. M. C.; MEDINA, A.; SEVERINO, D.; HOCH FEHLAUER-ALE, K.; ARIJO, S. "Proteomic approach for the evaluation of the effects of polyaromatic hydrocarbons (PAHs) irradiated in the marine fish Rachycentron canadum”. In: SETAC Europe 23rd Annual Meeting in Glasgow, UK, 12-16 May 2013. 
SANCHES, E. G.; SECKENDORFF, R. W.; HENRIQUES, M. B.; FAGUNDES, L.; SEBASTIANI, E. F. Viabilidade econômica do cultivo do Bijupira (Rachycentron canadum) em sistema offshore, Info. Econômicas, v. 38, p. 42-51, 2008.

SANTOS, A. A. et al. Análise histopatológica de fígado de Tilápia do Nilo, Oreochromis niloticus, criada em tanque-rede na Represa de Guarapiranga, São Paulo, SP, Brasil. Boletim técnico do Instituto de Pesca, v. 30, p. 141-145, 2004.

SANTOS, S. G. et al. Alterações histológicas em brânquias de tilápia nilótica Oreochromis niloticus causadas pelo cádmio. Arquivo Brasileiro de Medicina Veterinaria e Zootecnia, Portugal, v. 59, n. 2, p. 376-381, 2007.

SILVA, J. R. M. C.; STAINESS, N. A.; BLAZQUEZ, J. H.; PORTONETO, L. R. ; BORGES, J. C. S. Phagocytosis and giant cell formation at 0oC by macrophage (M0) of Nototheniacoriiceps. Journal of Fish Biology, v. 60, p. 466-478, 2002.

SILVA, R. R.; SOARES-JUNIOR, R. P.; SOUZA-FERREIRA, A. C. Danos ambientais: reconhecimento, mensuração e evidenciação contábil no setor petrolífero. In: $1^{\circ}$ South Congresson Social and Environ. Account. Research. 2009.

SILVEIRA, U. S.; LOGATO, P. V. R.; PONTES, E. C. Utilização e metabolismo dos carboidratos em peixes. Revista eletrônica Nutritime, v. 6, p. 817-836, 2009.

TAKASHIMA, F.; HIBIYA, T. An atlas of fish histology normal and pathological features. 2.ed. Kodansha: Gustav Fischer Verlag, 1995. [160 p.].

TEIXEIRA, F.; GUERRA, O. A competitividade na cadeia de suprimento da indústria de petróleo no Brasil. Revista Economia Contemporânea. v. 7, p. 263-268, 2003.

TIBURTIUS, E. R. L., ZAMORA P. P. Contaminação de águas por BTXs e processos utilizados na remediação de sítios contaminados. Quimica Nova, v. 27, p. 441-226, 2004.

TIIHONEM, K.; NIKINMAA, M; LAPPIVAARA, J., Glucose transport in carp erythrocytes: individual variation and effects os osmotic swelling, extracellular $\mathrm{pH}$ and catecholamines. The Journal of Experimental Biology, v. 198, p. 577-583, 1995.

THOPHON, S.; KRUATRACHUE, M.; UPATHAM, E. S.; POKETHITIYOOK, P. SAHAPHONG, S.; JARITKHUAN, S. Histopathological alterations of white seabass, 
Latescalcarifer, in acute and suchonic cadmium exposure. Environmental Pollution, v. 121, p. 307-320, 2003.

VIEIRA V. C. C.; SEVERINO, D. ; OliVEIRA Jr., O. N., PAVINATTO, F. J. ; ZANIQUELLI, M. E. D. ; RAMOS, A. P.; BAPTISTA, M. S. Langmuir Films of Petroleum at the Air-Water Interface. Langmuir, v. 25, n. 21, p. 12585-12590, 2009.

VIJAYAN, M. M.; RAPTIS, S. SATHIYAA, R. Cortisol treatments affects glucocorticoid receptor and glucocorticoid-responsive genes in the liver of rainbow trout. General and Comparative Endocrinology, v. 132, p. 256-263, 2003.

WENDEELAR BONGA, S. E. The stress response in fish. Physiology Reviews., v. 77, p. 591-625, 1997.

WESTER, P. W.; VAN DER VEM, L. T. M.; VETHAAK, A. D.; GRINWIS, G. C. M.; VOS, J. C. Aquatic toxicology: opportunities for enhancement through histopatathology. Environmental Toxicology and Pharmacology, v. 11, p. 289-295, 2002.

WINKAlER, E. U., Silva, A. G., CHAiCOSKI, H. G., MARTINEZ, C. B. R., Biomarcadores histológicos e fisiológicos para o monitoramento da saúde de peixes de ribeirões de Londrina, Estado do Paraná. Acta Scientiarum, v. 23, p. 507-514, 2001.

WISEMAN, S.; OSACHOFF, H.; BASSET, E.; MALHOTRA, J.; BRUNO, J.; VANAGGELEN, G.; MOMMESEN, T. P.; VIJAYAN, M. M. Gene expression pattern in the liver during recovery from an acute stressor in rainbow trout. Comparative Biochemistry and Physiology Part. D. Genomics and Proteomics, v. 2, p. 234-244, 2007.

ZANIBONI, E. F., WEINGARTNER M., Técnicas de indução da reprodução de peixes migradores, Induced breeeding in migratory fishes, Revista Brasileira de Reprodução Animimal, v. 31, p. 367-373. 2007. 